\title{
Spatial and temporal distributions of turbulence under bichromatic breaking waves
}

Postprint of manuscript published in Coastal Engineering

\author{
Joep van der Zanden ${ }^{1,2}$, Dominic A. van der A³ , Iván Cáceres" Bjarke Eltard Larsen5, \\ Guillaume Fromant ${ }^{6}$, Carmelo Petrotta ${ }^{7}$, Pietro Scandura ${ }^{8}$, Ming $\mathrm{Li}^{9}$,
}

\begin{abstract}
1) Department of Water Engineering and Management, University of Twente, Enschede, PO Box 217, 7500 AE, The Netherlands

2) Offshore Department, Maritime Research Institute Netherlands (MARIN), Haagsteeg 2, 6708 PM

Wageningen

3) School of Engineering, University of Aberdeen, Aberdeen, AB24 3UE, United Kingdom

4) Laboratori d’Enginyeria Marítima, Universitat Politècnica de Catalunya, 608034 Barcelona, Spain

5) Technical University of Denmark, Department of Mechanical Engineering, Section of Fluid Mechanics, Coastal and Maritime Engineering, DK-2800, Kgs. Lyngby, Denmark

6) LEGI, CNRS, University of Grenoble Alpes, Grenoble-INP, 38041 Grenoble, France

7) Department of Engineering, University of Messina, C. da di Dio, 98166 S. Agata, Messina, Italy

8) Department of Civil Engineering and Architecture, University of Catania, Via Santa Sofia 64, 95123 Catania, Italy

9) School of Engineering, University of Liverpool, Liverpool, England L69 3GQ, United Kingdom
\end{abstract}

Keywords: Turbulence, breaking waves, surf zone, wave groups, bichromatic waves, wave flume experiment

The full reference of this paper reads:

van der Zanden, J., van der A, D. A., Cáceres, I., Larsen, B. E., Fromant, G., Petrotta, C., Scandura, P., \& Li, M. (2019). Spatial and temporal distributions of turbulence under bichromatic breaking waves. Coastal Engineering, 146, 65-80. https://dx.doi.org/10.1016/j.coastaleng.2019.01.006 


\begin{abstract}
The present study aims to extend insights of surf zone turbulence dynamics to wave groups. In a large-scale wave flume, bichromatic wave groups were produced with $31.5 \mathrm{~s}$ group period, 4.2 $\mathrm{s}$ mean wave period, and a $0.58 \mathrm{~m}$ maximum wave height near the paddle. This condition resulted in plunging-type wave breaking over a fixed, gravel-bed, barred profile. Optic, acoustic and electromagnetic instruments were used to measure the flow and the spatial and temporal distributions of turbulent kinetic energy (TKE). The measurements showed that turbulence in the shoaling region is primarily bed-generated and decays almost fully within one wave cycle, leading to TKE variations at the short wave frequency. The wave breaking-generated turbulence, in contrast, decays over multiple wave cycles, leading to a gradual increase and decay of TKE during a wave group cycle. In the wave breaking region, TKE dynamics are driven by the production and subsequent downward transport of turbulence under the successive breaking waves in the group. Consequently, the maximum near-bed TKE in the breaking region can lag the highest breaking wave by up to 2.5 wave cycles. The net cross-shore transport of TKE is in the shoaling region primarily driven by short-wave velocities and is shoreward-directed; in the wave breaking region, the TKE transport is seaward-directed by the undertow and the longwave velocities. Downward transport of TKE is driven by the vertical component of the timeaveraged flow. The cross-shore and vertical diffusive transport rates are small relative to the advective transport rates.
\end{abstract}




\section{Introduction}

Over the last decades, turbulence under breaking waves has been of vast scientific interest because of its effects on near-shore morphodynamics. Several studies have reported the entrainment of significant amounts of sediments by breaking waves (Nielsen, 1984; Yu et al., 1993; Beach \& Sternberg, 1996), and recent studies have attributed this to wave breaking turbulence that reaches the bed (Scott et al., 2009; Aagaard \& Hughes, 2010; Sumer et al., 2013; Otsuka et al., 2017). The timing of wave breaking turbulence arrival at the bed has significant implications for the phase-dependent pickup of sediment (Yoon \& Cox, 2012; Brinkkemper et al., 2017), and the advection of suspended grains is closely related to the transport of TKE (LeClaire \& Ting, 2017; van der Zanden et al., 2017). Consequently, in order to assess the effects of wave breaking on near-shore morphodynamics, knowledge of the spatial and the temporal distribution of wave breaking turbulence is considered important.

The present study considers plunging breaking waves, which are characterized by the forward curling front of the overturning wave. The flow field under plunging waves has been extensively documented (e.g. Peregrine, 1983; Okayasu et al., 1986; Battjes, 1988; Lin \& Hwung, 1992). These studies showed that the curling wave front transforms into a jet that impinges the water surface and invades the water column. Upon wave breaking, part of the irrotational wave motion is transformed into a rotational vortex motion. The shear around the plunging jet and the breakup of the organized vortex leads to the production of turbulence in the water column. It should be noted that different types of wave breaking exist, with plunging and spilling being the predominant types. Under plunging breakers, breakinggenerated turbulence is transported more quickly down to the bed and mixing rates are higher than for spilling breakers (Ting and Kirby, 1995, 1996). For these reasons, plunging breaking waves may be expected to have a stronger and more direct effect on surf zone sediment transport than spilling breakers and are therefore selected for the present study.

The spatial and temporal distributions of turbulence under plunging waves have been measured extensively in laboratory wave flumes at small scale, mostly over plane-sloping beds (Nadaoka \& Kondoh, 1982; Ting \& Kirby, 1995; Chang \& Liu, 1999; Stansby \& Feng, 2005; De Serio \& Mossa, 2006; Lara et al., 2006; Govender et al., 2011) with the exception of the barred bed study by Boers (2005), and at large scale over barred bed profiles (Scott et al., 2005; Yoon \& Cox, 2010; Brinkkemper et al., 2016; van der Zanden et al., 2016; van der A et al., 2017). These studies revealed strong spatial variation with highest turbulent kinetic energy (TKE) in the breaking region near the water surface. From here, turbulence spreads vertically and horizontally. The vertical transport is downward due to diffusion by large eddies (Ting \& Kirby, 1995) and as a result of advection by the vertical component of the mean flow in the breaking region (van der A et al., 2017). The magnitude and direction of the cross-shore transport of TKE depends strongly on breaking characteristics and the responsible transport mechanism, which can be diffusion (Ting \& Kirby, 1995), wave-related advection (De Serio \& Mossa, 2006) or current-related advection by the undertow (van der A et al., 2017).

The flow in the surf zone is horizontally and vertically non-uniform, which in the presence of wave breaking turbulence enhances turbulence production in the water column (van der Zanden et al., 2018). The time-dependent transport and production rates lead to a strong temporal variation in TKE. Studies involving waves breaking over a plane-sloping bed have revealed a sharp increase in TKE directly under the wave front, followed by a nearly complete decay within one wave cycle (Okayasu et al., 1986; Ting \& Kirby, 1995; De Serio \& Mossa, 2006). However, turbulence under plunging waves at deep water (Melville et al., 2002) and over a breaker bar trough (van der A et al., 2017) can take over a few wave cycles to dissipate fully. TKE can be maximum during the wave crest (Okayasu et al., 1986; Ting \& 
Kirby, 1995; De Serio \& Mossa, 2006; Brinkkemper et al., 2016) or wave trough half-cycle (Boers, 2005; van der A et al., 2017), depending on cross-shore location, breaking process, and bed geometry.

With the increase of computational power, advanced numerical models have been used to simulate wave breaking in recent years. Numerous studies have applied Reynolds-Averaged Navier-Stokes (RANS) models to reproduce time-varying TKE (Lin \& Liu, 1998) as well as spatial distributions of timeaveraged TKE at outer flow levels (Bradford, 2000; Xie, 2013; Jacobsen et al., 2014; Brown et al., 2016) and inside the wave bottom boundary layer (Fernandez-Mora et al., 2016). Large Eddy Simulations (LES) have become increasingly important and are capable to reproduce the formation and transport of coherent structures during the breaking process (Christensen \& Deigaard, 2001; Watanabe et al., 2005; Zhou et al., 2017). Although qualitatively successful, both approaches report a consistent overestimation of the modelled TKE in the pre-breaking and the wave breaking regions. This is due to the problem being physically challenging and requiring an appropriate model set-up for both the small-scale, bedgenerated turbulence, as well as for the large-scale, breaking-generated turbulence. Although LES models are expected to resolve the large scales, the modeling of sub-grid processes often relies on similar parameterizations as in RANS models.

A recent study by Larsen and Fuhrman (2018) shows how the overestimation of turbulence pre-breaking comes from an instability problem for RANS models when applied to free-surface waves. An improved model that eliminates the problem was analytically derived and numerically tested, showing significant improvements in modelled turbulence levels as well as in undertow profiles in the pre-breaking and initial breaking regions (Larsen \& Fuhrman, 2018). Zheng et al. (2017) revealed that the spatial distributions of TKE across the breaking region can be produced by turbulence closure models, if a cross-shore varying dissipation factor is applied. Though advances in numerical modelling of breaking waves have been made recently, these models can still be improved and the work towards better numerical models will benefit from high-resolution validation measurements of turbulence in various breaking wave conditions.

The majority of the aforementioned experimental studies involved regular breaking waves. Although such waves allow a detailed examination of intra-wave TKE, the continuous injection of turbulence into the water column by each passing wave and the steep cross-shore undertow gradients that develop are not fully representative for waves at natural beaches. On the other hand, studying the temporal variability of TKE under random breaking waves requires phase-averaging over a range of different waves (e.g. Brinkkemper et al., 2016; Christensen et al., 2018), which makes the results susceptible to relatively high measurement uncertainty. Furthermore, while waves at natural beaches tend to arrive in groups, this grouping nature of waves has not been considered in most previous studies. Therefore, the present study aims to shed more insights in the dynamics of surf zone turbulence under wave groups. The specific research objective is to quantify the spatial and temporal distributions and the dominant transport mechanisms of TKE under breaking wave groups. This is achieved by measuring the flow and turbulence under repeating bichromatic wave groups in a large-scale wave flume. Here the flow at the bed, in contrast to many small scale experiments, can be considered fully turbulent, but generated waves are still smaller than at field scale.

The wave flume experiments, measurements and data treatment are described in Section 2. The water surface elevation and flow velocity measurements are discussed in Sections 3 and 4, respectively. Section 5 presents measurements of the spatial and temporal turbulence distributions and of the net cross-shore and vertical transport of TKE. Section 6 discusses the results and the conclusions are summarized in Section 7. 


\section{Experiments}

\subsection{Experimental setup and test conditions}

The experiments were conducted in the $100 \mathrm{~m}$ long, $3 \mathrm{~m}$ wide and $5 \mathrm{~m}$ deep wave flume at the Polytechnic University in Barcelona. The primary motivation for conducting the experiments at large scale was to establish a wave bottom boundary layer (WBL) flow that is in the same turbulent regime as on natural beaches. Detailed measurements of the WBL flow were obtained but are not considered in the present manuscript.

Figure 1 shows the experimental set-up. The cross-shore coordinate $x$ is defined positively towards the beach with its origin at the toe of the wave paddle in rest position; the transverse coordinate $y$ is defined positively towards the center of the flume with its origin at the right-hand flume wall when facing the beach; the vertical coordinate $z$ is defined positively upward from the still water level (swl). The water depth $h$ in the deeper part of the flume is $2.65 \mathrm{~m}$. The bed profile consisted of a 1:12 offshore slope, followed by a breaker bar and trough, a $10 \mathrm{~m}$ long gently sloping (1:125) section, terminated by a 1:7 sloping beach. The breaker bar is $0.6 \mathrm{~m}$ high (measured from crest to trough). This bed profile resulted from a preceding experiment and was formed by running regular waves over an in initially horizontal, mobile, medium-sand test section for 3 hours (van der Zanden et al., 2016). The bed profile was then fixed by replacing the top layer of sand by a $0.20 \mathrm{~m}$ thick layer of concrete, as described by Van der A et al. (2017). In the resulting bed profile, the breaker bar and trough are well separated from the beach, which isolates the wave-breaking-related processes from the processes occurring around the shoreline and in the swash zone. It should be noted that the bed profile was formed by regular waves rather than bichromatic waves and therefore cannot be considered the equilibrium bed profile of the present experiment. The profile was chosen for convenience, as the concrete bed was already present in the flume, and to facilitate comparison with wave breaking turbulence observations over the same bed profile for regular waves (van der A et al., 2017; van der Zanden et al., 2018).

Prior to the present experiment, in order to increase the WBL thickness and therefore increase the spatial resolution of measurements in the WBL, the bed roughness was increased by gluing a single layer of gravel to the concrete bed surface. This commercial gravel mixture had a median diameter $D_{50}=9.0$ mm, with $D_{10}=7 \mathrm{~mm}$ and $D_{90}=13 \mathrm{~mm}$, and was classified as 'well-sorted, medium gravel' (following Folk \& Ward, 1957; Blott \& Pye, 2001). The gravel was uniformly spread over the profile and was glued firmly to the concrete using epoxy resin.

The wave condition was a bichromatic wave which leads to well-defined repeating wave groups that induce velocity oscillations at short- and wave-group time scales. In addition, the repeating wave conditions allow velocity decomposition based on ensemble-averaging at the wave group time scale. The bichromatic wave had frequency components $f_{1}=0.25 \mathrm{~Hz}$ and $f_{2}=0.22 \mathrm{~Hz}$, resulting in a wave group with group period $T_{\mathrm{gr}}=31.5 \mathrm{~s}$ that consisted of 7.5 short waves with mean period $T_{\mathrm{m}}=4.2 \mathrm{~s}$. The measured maximum wave height near the wave paddle (at $x=11.8 \mathrm{~m}$ ) was $H_{\max }=0.58 \mathrm{~m}$. Steering signals for the wave paddle were based on first-order wave generation theory. The wave paddle did not have absorption and flume seiching effects were corrected for in the data processing (see Section 2.4). To ensure sufficient convergence of phase-averaged quantities, each experimental "run" involved 58 minutes of wave generation. Wave conditions across the flume and the wave breaking process are described in detail in Section 3. 


\subsection{Measurements}

The water surface elevation was measured at a sampling frequency $f_{\mathrm{s}}=40 \mathrm{~Hz}$ with resistive wave gauges (RWGs) at 12 cross-shore locations and with acoustic wave gauges (AWGs) at 52 locations (Figure 1a). In addition, pressure transducer (PT) measurements of the dynamic pressure at 28 cross-shore locations were used to retrieve the water surface level by applying the non-linear weakly dispersive approach by Bonneton et al. (2018). For the present experiment, this approach yielded a better agreement with the AWG and WG recordings compared to the linear approach by Guza \& Thornton (1980). The approach by Bonneton et al. (2018) involves taking second order time derivatives of the pressure, and therefore a cut-off frequency of $1 \mathrm{~Hz}$ was used in the reconstruction to limit spurious oscillations in the reconstruction (similar to Bonneton et al., 2018). The PTs were primarily applied in the breaking region, where the RWGs and AWGs suffer from spurious measurements due to bubbles and splash-up of water.

Velocities were measured using two laser Doppler anemometers (LDAs), two acoustic Doppler velocimeters (ADVs), and two electromagnetic current meters (ECMs), deployed from a measurement frame attached to a carriage atop of the flume (Figure 2). This "mobile frame" could be repositioned at any elevation (with $\mathrm{mm}$ accuracy) and cross-shore location (with $\mathrm{cm}$ accuracy); detailed specifications are provided by Ribberink et al. (2014). Velocities in cross-shore, transverse and vertical direction are defined $u, v$ and $w$, respectively.

The LDAs were two Dantec two-component backscatter LDA systems, each consisting of a $14 \mathrm{~mm}$ diameter submersible transducer probe with $50 \mathrm{~mm}$ focal length and powered by a $300 \mathrm{~mW}$ Ar-Ion aircooled laser. The LDAs measured the $u$ and $w$ components in ellipsoidal-shaped measurement volumes of $115 \mu \mathrm{m}$ maximum diameter and approximately $2 \mathrm{~mm}$ length in the $y$ direction. The LDA sampling frequency depends on seeding particle density and flow velocity and varied between $f_{\mathrm{s}}=150 \mathrm{~Hz}$ and $670 \mathrm{~Hz}$, with $f_{\mathrm{s}}=332 \mathrm{~Hz}$ on average, for the present experiment.

The two ADVs measured the three-component velocity at $f_{\mathrm{s}}=100 \mathrm{~Hz}$. The lower ADV ("ADV1" in what follows) was a side-looking Nortek Vectrino, while the upper ADV (“ADV2" in what follows) was a downward-looking Nortek Vectrino+ (Figure 2). The cylindrical shaped measurement volumes of the ADVs was $6 \mathrm{~mm}$ in diameter and $2.8 \mathrm{~mm}$ in the $y$-direction. The two disc-shaped ECMs, custombuilt by Deltares, measured the $u$ and $w$ component at $f_{\mathrm{s}}=40 \mathrm{~Hz}$ over a cylindrical shaped measurement volume of approximately $1 \mathrm{~cm}$ diameter.

By repositioning the frame to a different location and elevation for each 58-min run, a high spatial coverage of velocity measurements was obtained (Figure 1b). After discarding spurious data (see next Section), the remaining velocity measurements covered $201 x, z$ locations. These measurements were collected during 48 runs, covering 22 cross-shore locations and involving one to three elevations of the mobile frame per location. At each cross-shore location, velocity profiles were measured with approximately $0.1 \mathrm{~m}$ vertical increments and with the lowest measurement (LDA) at $0.025 \mathrm{~m}$ above the local bed level $z_{\text {bed }}$. The latter was accomplished by lowering the frame while manually measuring the distance between the LDA probe and $z_{\text {bed, }}$, where $z_{\text {bed }}$ is defined as the top of the roughness elements over a $0.3 * 0.3 \mathrm{~m}^{2}$ area. Measurements of the WBL velocity profile indicated that the lowest LDA measurement at $z-z_{\text {bed }}=0.025 \mathrm{~m}$ is located approximately at the WBL overshoot elevation.

\subsection{Data processing}

The AWG measurements of the water surface elevation were despiked using a phase-space algorithm that was originally developed for despiking of ADV data (Goring \& Nikora, 2002; Mori et al., 2007). 
Spurious velocity recordings by the $\mathrm{ADV}$, for instance due to air bubble presence, were identified as having a signal-to-noise (SNR) ratio below 7 or a correlation value below $50 \%$. In addition, measurements that deviated from more than five times the phase-averaged root-mean-square velocity were identified as outliers. These spurious measurements and outliers were discarded and not replaced. The EMCs provide erroneous measurements when the probe is emerged or close to the water surface. Therefore, EMC data were discarded when the probe was above, or within $0.35 \mathrm{~m}$ below, the locally measured instantaneous water surface elevation. The LDA data are SNR-validated instantaneously during acquisition and suffered from less spurious measurements than the ADVs and EMCs. The water surface and velocity recordings were decomposed into a long-wave and short-wave component using an $8^{\text {th }}$-order zero phase Butterworth filter with cut-off frequency $f=0.1 \mathrm{~Hz}$. The low-frequency $(f<0.1 \mathrm{~Hz})$ and high-frequency $(f>0.1 \mathrm{~Hz})$ components are annotated with subscripts "If" and "hf", respectively. In what follows, the low- and high-frequency components denote oscillations at time scales of the wave group and of the short waves, respectively.

The velocity time series showed that the undertow, defined as the cross-shore velocity time-averaged over a wave group, required approximately three wave group cycles to develop to an equilibrium magnitude. Data corresponding to the first 5 min (approximately 10 wave groups) were discarded and the remaining data, i.e. approximately 100 wave groups corresponding to a hydrodynamic equilibrium, were used for phase-averaging. Although the wave paddle steering signal was the same for all generated wave groups, it should be noted that the wave groups and short waves arriving at the test section did not all have the exact same wave (group) period, due to slight differences in wave generation at the paddle and in propagation speeds due to flume seiching. In order to obtain optimum phase correspondence of all wave repeats, phase-averaged quantities were evaluated for each of the seven short waves that form the group individually. Phase-averaged velocities over $N$ wave groups are annotated with angular brackets and were computed following a conditional averaging method (e.g. Petti \& Longo, 2001):

$$
\langle u(t)\rangle_{i}=\frac{1}{N} \sum_{n=0}^{N-1} u\left(t+t_{n, i}\right) \quad 0 \leq t<T_{i}
$$

Here, $\langle u(t)\rangle_{i}$ is the phase-averaged velocity for short wave $i$ (with $i=1,2, . ., 7$ ); $t_{n, i}$ is the start of the $n^{\text {th }}$ repeat of the $i^{\text {th }}$ short wave, which was calculated as the upward zero crossing of the measured water surface elevation at $x=50.9 \mathrm{~m}$. The seven phase-averaged velocities $\langle u(t)\rangle_{i}$ for the short waves were then combined into one phase-averaged velocity $\langle u(t)\rangle$ for the wave group. Due to the irregular sampling, the LDA data were phase-averaged over small intervals $\Delta t=0.01 \mathrm{~s}$, while accounting for particle residence time, corresponding to a same sampling frequency similar to the ADVs. All phase-averaged data were time-referenced such that $t / T_{\mathrm{gr}}=0$ corresponds to the passage of the front of the wave group at the most offshore mobile frame location, $x=49.0 \mathrm{~m}$ (unless stated differently).

The velocity time series $u$ was then decomposed into a time-averaged component $\bar{u}$ and a periodic component $\tilde{u}=\langle u\rangle-\bar{u}$, that is further decomposed into long-wave and short-wave components $\tilde{u}_{\text {lf }}$ and $\tilde{u}_{\mathrm{hf}}$. For elevations above wave trough level, $\bar{u}$ is calculated over the 'wet' fraction of the wave cycle. The turbulent velocity $u$ ' was obtained using a Reynolds decomposition based on the phase-averaged velocity, which is arguably the most well-defined method for separating the turbulent velocity from the mean (Svendsen, 1987). In the present study, $u^{\prime}$ is calculated using the high-pass-filtered velocity time series as $u^{\prime}=u_{\mathrm{hf}}-\left\langle u_{\mathrm{hf}}\right\rangle$. By using $u_{\mathrm{hf}}$ instead of $u$, velocity fluctuations at frequencies lower than $0.1 \mathrm{~Hz}$ 
(e.g. due to flume seiching and variability between wave groups) do not contribute to the turbulence time series.

The contribution of wave bias (also termed 'pseudo-turbulence', e.g. Scott et al., 2005) to the turbulent velocity can be assessed through Figure 3, which shows the power spectral densities of a velocity measurement by the LDA. PSDs are shown of the untreated velocity $u$ (blue line) and of the turbulent velocity $u$ ' obtained after data cleaning, filtering, and decomposition (black line). The PSD of $u$ reveals significant energy at $f=0.03 \mathrm{~Hz}\left(=1 / T_{\mathrm{gr}}\right)$ and at $f=0.2$ to $1.2 \mathrm{~Hz}$, which corresponds to the frequencies of the short waves and their higher harmonics. After filtering and decomposition, the energy at the wave group and at the short wave frequencies is almost entirely removed. This is illustrated by the PSD of $u$ ', which follows a well-established $-5 / 3$ slope at a double log axis, consistent with energy-transferring turbulent vortices in the inertial subrange (Pope, 2000).

A slight peak in the PSD of $u$ ' is still observed around $f=0.5 \mathrm{~Hz}$, which likely indicates that some energy of the short waves is still present in $u$ ' (i.e., wave bias). The wave bias contribution to $u$ ' was estimated from the PSD in two steps. Firstly, the variance of $u$ ' was obtained by trapezoidal integration of the PSD over the full frequency range. Secondly, the peak around $f=0.5 \mathrm{~Hz}$ in the spectrum was removed, the spectrum was linearly interpolated (at double log axes), and the variance was estimated once more. The quantified wave bias contribution to the total variance was $3 \%$, which is considered acceptable.

The same decomposition was applied to $v$ and $w$. Turbulence intensities $u_{\mathrm{rms}}^{\prime}, v_{\mathrm{rms}}^{\prime}$ and $w_{\mathrm{rms}}^{\prime}$ were then calculated as the root-mean-square (rms) value at a phase instant, and were used to calculate the turbulent kinetic energy $k$ as:

$$
\langle k\rangle=\frac{1}{2}\left(\left\langle u_{\text {rms }}^{\prime}\right\rangle^{2}+\left\langle v_{\text {rms }}^{\prime}\right\rangle^{2}+\left\langle w_{\text {rms }}^{\prime}\right\rangle^{2}\right)
$$

For the two-component LDA measurements, $k$ was calculated instead as

$$
\langle k\rangle=\frac{1.33}{2}\left(\left\langle u_{\mathrm{rms}}^{\prime}\right\rangle^{2}+\left\langle w_{\mathrm{rms}}^{\prime}\right\rangle^{2}\right)
$$

where the factor 1.33 was proposed by Stive and Wind (1982) and Svendsen (1987) for surf zone turbulence. The use of this factor is supported by ADV measurements in the present study that indicate a mean factor of $1.32(+/-0.05)$ in the breaking region. Finally, the turbulent Reynolds shear stress was calculated as $-\left\langle u^{\prime} w^{\prime}\right\rangle$.

The EMC measurements could not provide accurate turbulence estimates in the present conditions, due to their relatively low sampling frequency and their large measurement volume. In addition, by comparing the turbulence intensities measured by LDA and ADV, it was found that the vertical velocity measured by ADV1, due to its sideward-looking orientation, suffered from high contributions of acoustic Doppler noise. These noise contributions, which could not be removed, led to an overestimation of $k$. Therefore, the TKE measurements by ADV1 were discarded, leaving the measurements by LDA1, LDA2 and ADV2 for the analysis of turbulence.

\section{Water surface elevation}

Time series of the phase-averaged water surface elevation $\eta$ at three cross-shore locations are shown in Figure 4a-c. To facilitate a good inter-comparison, the time series in the present representation were time-referenced such that $t / T_{\mathrm{gr}}=0$ corresponds to the passage of the front of the group at each location. The grey contour around the lines marks + /- one standard deviation. This contour is barely visible, which 
indicates the excellent repeatability of the wave groups. The mean variability of $\langle\eta\rangle$ over all measurements is less than $0.01 \mathrm{~m}$.

Figure 4a shows that after generation, the short waves forming the wave group are slightly skewed (crests higher than troughs) and approximately symmetric. As the wave group propagates over the slope, the short waves become higher, more skewed, and more asymmetric ('sawtooth-shaped'). At $x=50.9$ $\mathrm{m}$ (Figure $4 \mathrm{~b}$ ), which is in the shoaling region before wave breaking, the wave group consists of seven well-defined short waves. Visual observations and video recordings reveal that the five highest short waves broke over the bar as plunging-type breakers. These visual observations were used to detect the "plunge point", i.e. the location where the plunging jet first strikes the water surface (Peregrine, 1983), with approximately $0.5 \mathrm{~m}$ accuracy. Waves two to six were found to break at $x=58.5,57.5,56.5,57.5$ and $57.5 \mathrm{~m}$, respectively, while the first and seventh short waves broke at the shoreline. The "break point" (where the wave starts to overturn) of the most offshore breaking wave was measured at $x=54.0$ $\mathrm{m}$, while the "splash point" (where the bounced jet strikes the water surface a second time) of wave two was located at $x=60.0 \mathrm{~m}$. Based on these visual observations and following terminology by Smith and Kraus (1991), we define the shoaling region $(x<54 \mathrm{~m}$ ), breaking region (54 $\mathrm{m}<x<60 \mathrm{~m}$ ), and inner surf zone $(x>60 \mathrm{~m})$. Hence, Figure $4 \mathrm{c}(x=66.0 \mathrm{~m})$ corresponds to the inner surf zone where waves two to six have broken and have transformed into surf bores. These five surf bores have similar wave heights, are highly skewed, and are significantly lower in wave height than at $x=50.9 \mathrm{~m}$.

Figure $4 \mathrm{~d}$ shows the cross-shore distribution of the maximum wave height $H_{\max }=\langle\eta\rangle_{\max }-\langle\eta\rangle_{\min }$. The three instruments yield generally consistent results, although the PTs tend to underestimate the wave height in the breaking region, where waves are strongly skewed and asymmetric, due to strong pressure attenuation of the higher harmonics of the wave. The wave heights are approximately constant over the horizontal, deeper part of the flume $(x<34 \mathrm{~m})$, except for some modulations that are attributed to wave reflection at the beach and at the offshore slope. As waves shoal over the offshore slope, the wave height increases up to $H_{\max }=0.90 \mathrm{~m}$ at $x=52.8 \mathrm{~m}$. It should be noted that the wave height in the breaking region may be underestimated as a result of the de-spiking routine applied to the AWG data, which smoothens the wave crests slightly. The maximum wave height decreases by about $50 \%$ between $x=$ $53.8 \mathrm{~m}$ and $59.6 \mathrm{~m}$ due to wave breaking. Between $x=60$ and $70 \mathrm{~m}$ the wave height remains approximately constant, while over the sloping beach $(x>70 \mathrm{~m})$ the waves shoal and break a second time.

As explained in Section 2.3, the water surface elevation was decomposed into a high-frequency and lowfrequency component. Figure 4 e shows the cross-shore distribution of $\langle\eta\rangle_{\mathrm{rms}}$ for both components. It can be seen that $\left\langle\eta_{\mathrm{hf}}\right\rangle_{\mathrm{rms}}$ is approximately uniform over the offshore slope, which indicates that the increase in $H_{\max }$ (Figure 4b) is primarily due to an increasing skewness of the waves. The low-frequency component $\left\langle\eta_{\mathrm{lf}}\right\rangle_{\mathrm{rms}}$ gradually increases between the wave paddle and the bar crest. This relates to shoaling of the long wave and to energy transfer from the short waves to the wave group, as explored in several detailed studies (Baldock et al., 2000; Janssen et al., 2003; Lara et al., 2011; de Bakker et al., 2015; Padilla \& Alsina, 2017). Both $\left\langle\eta_{\mathrm{lf}}\right\rangle_{\mathrm{rms}}$ and $\left\langle\eta_{\mathrm{hf}}\right\rangle_{\mathrm{rms}}$ decrease in the wave breaking region around the bar crest $(x \approx 55.0 \mathrm{~m})$. Such decrease at both high and low frequencies near the break point is consistent with several other laboratory studies (see Baldock, 2012, for an overview). The low-frequency wave energy increases across the inner surf zone towards the shoreline ( $x=55$ to $75 \mathrm{~m}$ ) as the wave groups shoal for the second time. 


\section{Flow velocities}

Time series of the phase-averaged cross-shore and vertical velocities $\langle u\rangle$ and $\langle w\rangle$ at eight cross-shore locations at a free-stream elevation $z-z_{\text {bed }} \approx 0.4 \mathrm{~m}$ are shown in Figure 5 . The time series reveal the strongly skewed-asymmetric shape of the short-wave-induced velocity at all locations. The orbital amplitude increases from $x=49.0$ to $54.0 \mathrm{~m}$ (shoaling region to bar crest). At $x=54.0 \mathrm{~m}$, the highest velocities in both onshore $(1.3 \mathrm{~m} / \mathrm{s})$ and offshore $(-1.1 \mathrm{~m} / \mathrm{s})$ direction occur. The orbital amplitude decreases strongly between $x=54.0$ and $58.0 \mathrm{~m}$ (bar crest to trough) due to a combination of wave energy dissipation and an increasing water depth. At the same time the magnitude of the undertow increases, leading to increasing durations of the negative (seaward-directed) flow half cycles. Towards $x=60.0$ to $64.0 \mathrm{~m}$ the undertow weakens and the duration of the positive (shoreward-directed) flow half cycles increases again.

Figure 5 further includes the low-frequency velocity $\left\langle\tilde{u}_{\mathrm{lf}}\right\rangle$ (dashed lines). The amplitude of the lowfrequency velocity shows a clear variation with cross-shore location. This is better illustrated through Figure 6, which shows the cross-shore variations of free-stream $\left\langle\tilde{u}_{\mathrm{hf}}\right\rangle_{\mathrm{rms}}$ and $\left\langle\tilde{u}_{\mathrm{ff}}\right\rangle_{\mathrm{rms}}$ around the bar. The amplitude of $\left\langle\tilde{u}_{\mathrm{ff}}\right\rangle$ is small in the shoaling region (e.g. $x=49.0 \mathrm{~m}$ ), but its magnitude increases in the breaking region at the bar crest $(x=54.0 \mathrm{~m})$ and reaches a maximum at $x=58.5 \mathrm{~m}$, which corresponds to the bar trough and is located about $1 \mathrm{~m}$ shoreward from the plunge point of the largest breaking waves. Further shoreward $(x>58.5 \mathrm{~m})$, the amplitude of $\left\langle\tilde{u}_{\mathrm{lf}}\right\rangle$ decreases. This cross-shore variation of $\left\langle\tilde{u}_{\mathrm{lf}}\right\rangle_{\mathrm{rms}}(x)$ differs from the variation of $\left\langle\eta_{\mathrm{lf}}\right\rangle_{\mathrm{rms}}(x)$ (Figure 4e), which indicates that the low-frequency velocity variations are not directly driven by the water surface level variations at the wave group frequency. Instead, the large $\left\langle\tilde{u}_{\mathrm{lf}}\right\rangle$ values for $x=57-59.5 \mathrm{~m}$ are explained by time variations in the return flow induced by the successive breaking waves: the return flow, averaged over a short wave cycle, is relatively low under the non-breaking waves and relatively high under the highest breaking waves, hence yielding a periodic velocity oscillation at the wave group time scale (see also, e.g., Holmes et al., 1997; Alsina and Caceres, 2011). The $\left\langle\tilde{u}_{\mathrm{lf}}\right\rangle$ oscillations in the surf zone can thus be interpreted as a wave to wave variation in "undertow" velocity, although it should be stressed that the term "undertow" is used in the present study for the longer-term (i.e., wave-group-averaged), and not for the short-wave-averaged, cross-shore velocity. Therefore, the $\left\langle\tilde{u}_{\mathrm{lf}}\right\rangle$ oscillations will simply be addressed as "low-frequency" or "long-wave" fluctuations, following, e.g., Alsina and Caceres (2011).

The spatial distribution of the time-averaged cross-shore velocity $\bar{u}$ is shown in Figure 7. The timeaveraged cross-shore velocity magnitude increases from $-0.05 \mathrm{~m} / \mathrm{s}$ in the shoaling region to a maximum of $-0.3 \mathrm{~m} / \mathrm{s}$ in the breaking region over the bar trough, followed by a decrease to $-0.2 \mathrm{~m} / \mathrm{s}$ in the inner surf zone. Mass continuity requires these cross-shore variations in time-averaged cross-shore velocity to be balanced by a time-averaged velocity in vertical direction $(\mathrm{d} \bar{u} / \mathrm{d} x=-\mathrm{d} \bar{w} / \mathrm{d} z)$. The measurements (not shown for brevity) do indeed confirm a downward $\bar{w}$ between $x=58$ and $60 \mathrm{~m}$ and an upward $\bar{w}$ between $x=56$ and $58 \mathrm{~m}$ with magnitudes between 0 and $0.1 \mathrm{~m} / \mathrm{s}$. Such clockwise (in the present $x, z$ view) mean flow circulations have been discussed in several surf zone studies (e.g. Dyhr-Nielsen \& Sorensen, 1970; Svendsen, 1984; Greenwood \& Osborne, 1990).

Note that $\bar{u}(x)$ follows a similar cross-shore variation as $\left\langle\tilde{u}_{\mathrm{lf}}\right\rangle_{\mathrm{rms}}(x)$ (Figure 6). This may be expected, as both velocity components are driven by the same processes, i.e., the effects of wave breaking on the mass and continuity balances. The location with strongest undertow magnitudes ( $x=58.5 \mathrm{~m}$ ) is located between 0 and $2 \mathrm{~m}$ shoreward from the plunge points of the five highest waves. This spatial lag is consistent with observations by Van der A et al. (2017) for regular plunging waves.

The undertow profiles in Figure 7 differ strongly in shape: around the bar crest ( $x=53$ to $56 \mathrm{~m}$, i.e. under wave break points) $\bar{u}(z)$ distributions tend to convex shapes, while $\bar{u}(z)$ over the bar trough $(x=$ 
58 to $61 \mathrm{~m}$, i.e. under splash points) increases strongly within the first few $\mathrm{cm}$ above the bed and tends to a concave shape at higher elevations. The variation of these undertow shapes, and their spatial occurrence relative to break and splash points, is consistent with previous observations of regular (e.g. Govender et al., 2011; van der A et al., 2017) and irregular (Boers, 2005) breaking waves over a bar.

\section{Turbulence}

This section provides insights into the spatial and temporal distributions of wave breaking turbulence. This is done by firstly examining the spatial distributions of the time-averaged TKE and Reynolds stress (Section 5.1). Subsequently, measurements of the time-dependent TKE are presented in Section 5.2 and are analyzed in more detail in Section 5.3. The net cross-shore and vertical transport of TKE is studied in Section 5.4.

\subsection{Time-averaged TKE and turbulent Reynolds stress}

The spatial distribution of the time-averaged turbulent kinetic energy $\bar{k}$ is shown in Figure 8a. For reference, the arrows mark the plunge points of the breaking waves, i.e. waves two to six in the wave group sequence as described in Section 3.

Similar to earlier observations of surf zone turbulence (see Introduction), $\bar{k}$ is strongly non-uniform, with values in the wave breaking region that are over an order of magnitude higher than those measured in the shoaling and inner surf zones. The region with highest $\bar{k}$ in the upper half of the water column $(x$ $=56-59 \mathrm{~m}$ ) corresponds to the plunge points of the breaking waves and to the region with the strongest decrease in short-wave energy. Hence, the increase in TKE is attributed to a transformation of wave energy to turbulent kinetic energy.

Close to the bed in the shoaling region up to the bar crest ( $x=49$ to $55.5 \mathrm{~m}$ ), the relatively high $\bar{k}$ near the bed represents contributions by bed-shear generated turbulence. However, despite the gravel bed being hydraulically (very) rough (following the classification of Jonsson, 1980), this bed-shear produced TKE is small compared to the TKE produced in the breaking region near the water surface. Maximum $\bar{k}$ at $z=-0.5 \mathrm{~m}$ is measured at $x=58 \mathrm{~m}$, which is about 0.5 to $1.5 \mathrm{~m}$ shoreward from the plunge points of the highest breaking waves in the group. A similar spatial lag was observed by Van der A et al. (2017) for regular waves. The measurements also reveal a high penetration depth of wave breaking turbulence into the water column, with wave breaking TKE that appears to stretch downward all the way to the bed ( $x=56$ to $60 \mathrm{~m}$ ). This is again consistent with observations for regular breaking waves (e.g. Cox \& Kobayashi, 2000; Scott et al., 2005; van der Zanden et al., 2016). The Froude-scaled TKE, defined as $\sqrt{\bar{k} / g h}$ where $g$ is the gravitational acceleration and $h$ the local water depth, varied between 0.015 and 0.03 in the wave breaking region. These non-dimensional TKE measurements are quantitatively compared with other studies in Section 6.

Figure $8 \mathrm{~b}$ shows the time-averaged turbulent Reynolds stress $-\overline{\left\langle u^{\prime} w^{\prime}\right\rangle}$. In the shoaling region up to the bar crest $(x=49$ to $55.5 \mathrm{~m}),-\overline{\left\langle u^{\prime} w^{\prime}\right\rangle}$ values are small but negative. Negative $-\overline{\left\langle u^{\prime} w^{\prime}\right\rangle}$ can be expected based on the velocity shear by the time-averaged cross-shore velocity ( $\mathrm{d} \bar{u} / \mathrm{d} z<0$, see Figure 7 ), hence suggesting that the time-averaged turbulent Reynolds stress in the shoaling region is produced by the undertow. Such negative $-\overline{\left\langle u^{\prime} w^{\prime}\right\rangle}$ has also been measured under shoaling laboratory waves by e.g. De Serio and Mossa (2013). The Reynolds stress changes sign and increases in magnitude in the wave breaking region, especially near the water surface between $x=57$ and $60 \mathrm{~m}$. The positive Reynolds stress in this region is associated with wave breaking turbulence, as follows from comparison with the distribution of $\bar{k}$ (Figure 8a), and is consistent with previous measurements of positive $-\overline{\left\langle u^{\prime} w^{\prime}\right\rangle}$ in the 
wave breaking region (Stansby \& Feng, 2005; De Serio \& Mossa, 2006; Ruessink, 2010; van der Werf et al., 2017). Despite the high positive Reynolds stresses high in the water column between $x=57$ and $60 \mathrm{~m}$, the stresses close to the bed are negative and are likely associated with bed-shear generated turbulence by the undertow. This is consistent with the observations by Van der Zanden et al. (2018), who found that $-\overline{\left\langle u^{\prime} w^{\prime}\right\rangle}$ inside the WBL may be negative despite strong positive $-\overline{\left\langle u^{\prime} w^{\prime}\right\rangle}$ at outer-flow elevations in wave the breaking region.

\subsection{Time-dependent TKE}

Figure 9 shows time series of phase-averaged TKE, $\langle k\rangle$, at four cross-shore locations and at two elevations: $z-z_{\text {bed }}=0.40 \mathrm{~m}$ and $0.025 \mathrm{~m}$. The latter corresponds roughly to the elevation of the velocity overshoot in the WBL.

In the shoaling region at $x=49.0 \mathrm{~m}$ and at $z-z_{\text {bed }}=0.025 \mathrm{~m}\langle k\rangle$ shows pairs of short-duration peaks (Figure 9b, grey line) that lag the maximum offshore- and onshore-directed velocity by approximately $0.2 T_{\mathrm{m}}$ (Figure 9a). These TKE peaks relate to turbulence that is produced at the bed during each halfcycle and that subsequently spreads upward. During the relatively long interval between the maximum onshore and maximum offshore velocity, i.e. under the rear side of the wave, $\langle k\rangle$ decays to nearly zero until the maximum velocity in offshore direction is reached and the process repeats as described. Hence, the transfer of TKE to the subsequent wave cycle is low and $\langle k\rangle$ is instead controlled by turbulence production and dissipation at the short-wave time scale. This is consistent with observations of negligible "time-history effects" of WBL turbulence in irregular flows in oscillatory flow tunnels (Bhawanin et al., 2014; Yuan \& Dash, 2017).

At the bar crest $(x=55.0 \mathrm{~m}$ ), near-bed $\langle k\rangle$ shows six well-defined peaks that are approximately in phase with the maximum onshore free-stream velocity (Figure 9c,d). The fact that only one peak in $\langle k\rangle$ appears per wave cycle, instead of two peaks such as at $x=49.0 \mathrm{~m}$, can be explained as follows. Firstly, maximum velocity magnitudes during the offshore half-cycles are substantially larger at $x=55.0 \mathrm{~m}$ than at $49.0 \mathrm{~m}$ and consequently, the TKE produced during the offshore half-cycle is greater and requires more time to dissipate. Secondly, the waves are much more asymmetric at $x=55.0 \mathrm{~m}$, leading to a shorter time interval between the maximum offshore and maximum onshore velocity, and thereby more "accumulation" of turbulence during the successive offshore and onshore half cycles. Similar to $x=49.0$ $\mathrm{m},\langle k\rangle$ decreases rapidly under the wave rear (offshore-to-onshore flow half cycles) and TKE has dissipated almost fully before a new production stage during the subsequent offshore half-cycle commences.

At the same location at $z-z_{\text {bed }}=0.40 \mathrm{~m}$ (Figure 9d, black line), $\langle k\rangle$ is substantially higher than at $x=$ $49.0 \mathrm{~m}$ (same elevation) which can be explained by wave breaking turbulence that is advected in offshore direction to this location (see also Figure 8a). Furthermore, $\langle k\rangle$ shows short-duration peaks during the upward zero crossings of the free-stream horizontal velocity. These peaks may be explained by the strong velocity shear that occurs during the offshore-to-onshore reversal under strongly asymmetric waves, contributing to a sudden and high local production of turbulence (van der Zanden et al., 2018).

Figure 9f shows $\langle k\rangle$ over the bar trough $(x=59.0 \mathrm{~m})$. At this location $\langle k\rangle$ is continuously higher at $z-$ $z_{\text {bed }}=0.40 \mathrm{~m}$ than at $0.025 \mathrm{~m}$, due to the injection of turbulence from the breaking waves. The TKE does not dissipate within one wave cycle, leading to a gradual build-up of TKE during the wave group cycle $\left(t / T_{\mathrm{gr}}=0.50\right.$ to 0.80$)$. Consequently, $\langle k\rangle$ shows a pronounced asymmetry at wave group time scale, with substantially higher TKE under the last three waves in the group $\left(t / T_{\mathrm{gr}}=0.75\right.$ to 0.05$)$ than under the first three waves $\left(t / T_{\mathrm{gr}}=0.20\right.$ to 0.50$)$. Three evident peaks in $\langle k\rangle$ are observed at $t / T_{\mathrm{gr}} \approx 0.65,0.80$, 
and 0.90. These peaks occur consistently under the rear of the short waves, i.e. around crest to trough reversal, when orbital velocities are downward-directed. Therefore, the occurrence of the peaks in $\langle k\rangle$ likely relates to an advective influx of TKE by the combined downward-directed time-averaged and periodic velocity (c.f. Figure $5 d$ ). $\langle k\rangle$ is maximum at $t / T_{\mathrm{gr}} \approx 0.8$, shortly after the fifth short wave in the wave group has passed. Note that the highest wave upon breaking is the fourth wave (passing $x=59.0$ $\mathrm{m}$ at $\left.t / T_{\mathrm{gr}}=0.6\right)$ and the maximum $\langle k\rangle$ thus lags this wave by about 1.5 short wave cycle. Near the bed (grey line) $\langle k\rangle$ shows a similar time variation at wave group scale, although less pronounced than at 0.40 m.

Figure 9h finally shows the time series of $\langle k\rangle$ in the inner surf zone $(x=64.0 \mathrm{~m})$. It follows that TKE at both elevations is continuously small with minor temporal variation at short-wave and wave-group time scales. These low turbulence levels occur despite the passage of the turbulent surface roller at this position, hence suggesting limited downward transfer from the roller to the flow at these elevations.

The temporal variation of TKE at wave group time scale is further explored in Figure 10, which shows the spatial distribution of $\langle k\rangle$ for seven instants of the wave group cycle. These instants match in terms of the phase of the short wave: from top to bottom, the seven panels correspond to the instant at which the crest of the seven short waves arrives at $x=62.0 \mathrm{~m}$. It is recalled that the first and last wave (top and bottom panels) passed the bar without breaking and that the fourth wave (middle panel) is the highest wave upon breaking. By inter-comparing the TKE distributions for each panel, the build-up and decay of TKE at wave group time scale under the successive breaking waves can be studied. The maximum $\langle k\rangle$ in the upper half of the water column in the breaking region $(x=54$ to $60 \mathrm{~m})$ is observed at $t / T_{\mathrm{gr}}=$ 0.78 . In the lower half of the water column, $\langle k\rangle$ is maximum at $t / T_{\mathrm{gr}}=0.92$. This shows that maximum $\langle k\rangle$ may lag the highest breaking wave by one to two wave periods $T_{\mathrm{m}}$, depending on cross-shore location and elevation. A similar time lag follows from analysing the minimum in $\langle k\rangle$ in the breaking region, which occurs during $t / T_{\mathrm{gr}}=0.38$. This corresponds to the passage of the second wave in the group and to a time lag of approximately $1.5 T_{\mathrm{m}}$ relative to the minimum of the wave group envelope. The crossshore variation of this time lag is explored in more detail in the next section.

\subsection{Temporal variability and time lagging of TKE}

The time series in the previous section show that TKE varies at time scales of the short wave and of the wave group. The aim of the present section is firstly to assess at which locations the highest temporal variability occurs, and whether TKE varies predominantly at the short-wave or at the wave-group time scale. Secondly, the time lag of near-bed TKE with respect to the wave group forcing is analyzed.

The temporal variability of TKE is quantified for each measurement through the coefficient of variation, $\langle\tilde{k}\rangle_{\mathrm{rms}} / \bar{k}$. High $\langle\tilde{k}\rangle_{\mathrm{rms}} / \bar{k}$ indicates large temporal variability, while $\langle\tilde{k}\rangle_{\mathrm{rms}} / \bar{k}=0$ corresponds to constant $\langle k\rangle$. Figure 11a shows the cross-shore and vertical distribution of $\langle\tilde{k}\rangle_{\mathrm{rms}} / \bar{k}$. Note that some data near the water surface were discarded when $\langle k\rangle$ time series were discontinuous because of emergence of the ADV probe or significant signal attenuation by bubbles. It follows from Figure 11a that the highest temporal variability in $\langle k\rangle$ occurs over the shoaling region up to the bar crest ( $x=49$ to $55.5 \mathrm{~m}$ ) within 0.20 to $0.30 \mathrm{~m}$ from the bed. Over the shoreward slope of the bar ( $x=55.5$ to $57.5 \mathrm{~m}$ ), TKE is relatively steady. Between $x=57.5$ and $59.5 \mathrm{~m}$, the temporal variability of TKE increases again over the whole water column. TKE variations here are attributed to the injection and downward transfer by the successive breaking waves. The inner surf zone $(x>60 \mathrm{~m})$ is characterized by a minor temporal variability in $\langle k\rangle$.

Important for our understanding of the temporal behavior of surf zone turbulence is whether the variations occur primarily at short- or at long-wave (wave group) frequencies. This is especially relevant 
near the bed, where the time-varying TKE can have important implications for suspended sand transport. For that reason, $\langle\tilde{k}\rangle$ is decomposed into short-wave (high-frequency) and long-wave (low-frequency) components $\left\langle\tilde{k}_{\mathrm{hf}}\right\rangle$ and $\left\langle\tilde{k}_{\mathrm{lf}}\right\rangle$, similar to the decomposition for water surface and velocity measurements (see Section 2.3). Figure 11b shows the coefficients of variation of $\langle\tilde{k}\rangle,\left\langle\tilde{k}_{\mathrm{hf}}\right\rangle$ and $\left\langle\tilde{k}_{\mathrm{lf}}\right\rangle$ at $z-z_{\text {bed }}=0.025$ $\mathrm{m}$ along the profile. It follows that the high variability in near-bed $\langle k\rangle$ between $x=49.0$ to $55.5 \mathrm{~m}$ is primarily explained by high-frequency variations, i.e. at short wave time scales. This corresponds to the time series at these locations, which suggested turbulence production and subsequent rapid dissipation during each wave cycle (see Section 5.2). Between $x=55.5$ and $57.0 \mathrm{~m}$ the temporal variability of $\left\langle\tilde{k}_{\mathrm{hf}}\right\rangle$ decreases, which relates directly to the decreasing orbital velocity amplitude over this region, hence leading to a reduction in bed shear stress and in the associated turbulence production. Between $x=57.0$ and $59.5 \mathrm{~m}$, the variability in $\langle k\rangle$ increases, especially due to variations at the wave group time scale as indicated by the increase in $\left\langle\tilde{k}_{\mathrm{lf}}\right\rangle_{\mathrm{rms}} / \bar{k}$. This suggests an increased buildup of TKE during the wave group, attributed to the wave breaking turbulent vortices that do not dissipate entirely within one wave cycle. This is again consistent with the time series of $\langle k\rangle$ discussed in Section 5.2. The measurements at $z-Z$ bed $=0.025 \mathrm{~m}$ show that the buildup of TKE during the wave group is not restricted to outer-flow elevations, but also occurs close to the bed, inside the WBL.

The TKE time series in Section 5.2 suggested a time lag of maximum TKE relative to the passage of the maximum wave. The timing of the maximum TKE within the group is relevant for time-varying sediment suspension, and consequently, for net sand transport and surf zone morphodynamics. For that reason, the time lag $\tau$ of near-bed TKE with $\eta$ was quantified by cross-correlating $\langle\tilde{k}\rangle$ at $z-z_{\text {bed }}=0.025$ $\mathrm{m}$ with the wave group envelope, which is defined as the vertical distance between the cubic interpolated crest and trough levels of the short waves (see Figure $4 \mathrm{~b}$ ). To prevent a bias due to the changing wave shape across the test section, all measured $\langle\tilde{k}\rangle$ time series were cross-correlated with the wave group envelope at $x=50.9 \mathrm{~m}$. The obtained $\tau$, which is the time lag at which the cross-correlation is maximum, was subsequently corrected for the changing phase of the wave group with cross-shore location by using the crest of the highest short wave as phase reference.

The time lag $\tau$ at $z-z_{\text {bed }}=0.025 \mathrm{~m}$, normalized by the short wave period $T_{\mathrm{m}}$, is shown in Figure 12a. The time-averaged TKE (Figure 12b) and the measurement positions over the bed (Figure 12c) are also shown for reference. In the shoaling region, $\tau$ varies between 0 and $1 \cdot T_{\mathrm{m}}$, indicating that $\langle k\rangle$ is approximately in phase with the wave group envelope. This is consistent with small-scale bed-generated turbulence that responds almost instantaneously to velocity forcing and has a high turnover rate, i.e. with limited buildup over the wave group. The time lag increases gradually over the breaking region, which is attributed to the arrival of external, wave-breaking-generated turbulence at the bed. Time lags of $\tau$ up to $2.5 T_{\mathrm{m}}$ are consistent with descriptions in Section 5.2 that also indicated that wave breaking turbulence requires a few wave cycles to arrive at the bed. The increasing $\tau$ from bar crest to trough $(x=55$ to 58 $\mathrm{m}$ ) suggests that the local water depth has an important effect on the time lag. However, the time lag is not only explained by the vertical distance to be covered, but also to other processes such as the vertical transport rate of TKE (next section) and the interaction of wave breaking turbulence with the flow. In the inner surf zone, $\tau$ reduces slightly. It should be noted that the time-averaged TKE and the variations of $\langle k\rangle$ are much smaller in the inner surf zone than in the breaking region, which makes the method more susceptible to measurement uncertainties. 


\subsection{TKE transport}

The net (i.e. time-averaged) local transport rate of TKE in horizontal and vertical directions are shown in Figure 13a $(\overline{u k})$ and Figure 13b $(\overline{w k})$. The transport over the shoaling region up to the bar crest is shoreward near the bed, and seaward at higher elevations. In the wave breaking region, the net transport of TKE is of higher magnitude and is negative over the whole water column. Cross-shore transport rates decrease in the inner surf zone where turbulence levels are much lower. The vertical transport is downward over $x=58$ to $60 \mathrm{~m}$ and upward between $x=54$ and $58 \mathrm{~m}$. The cross-shore and vertical transport rates in Figure 13a-b indicate a clockwise circulation of TKE in the wave breaking region, much alike the circulation observed by Van der A et al. (2017) for regular waves.

These observed net transport patterns can be further explained by decomposing the flux as

$$
\overline{u k}=\bar{u} \bar{k}+\overline{\tilde{u}_{\mathrm{hf}} \tilde{k}_{\mathrm{hf}}}+\overline{\tilde{u}_{\mathrm{lf}} \tilde{k}_{\mathrm{lf}}}+\overline{u^{\prime} k^{\prime}}
$$

where the right-hand terms denote, respectively, the transport contribution by the current, the short wave, the long wave, and by turbulent diffusion. Figure 14 shows the cross-shore transport rates by each of these four components. The current-related component (Figure 14a) is controlled by the undertow and is consequently seaward at nearly all locations. Highest magnitudes of $\bar{u} \bar{k}$ occur over the bar trough, where concurrent strong undertow velocities and high $\bar{k}$ are measured. The transport by short waves $\left(\overline{\tilde{u}_{\mathrm{hf}} \tilde{k}_{\mathrm{hf}}}\right)$ is significant, relative to the current-related contributions, only near the bed and between $x=49$ and $55.5 \mathrm{~m}$ (Figure 14b). This transport is shoreward-directed as the near-bed TKE is higher during the onshore-flow half-cycles (crest stage) than during the offshore-flow half-cycles (trough phase) of the short waves. Note that the total net TKE transport between $x=49$ and $55.5 \mathrm{~m}$ is shoreward-directed since the shoreward short-wave-related transport exceeds the seaward transport by the mean current (c.f. Figure 14a-b). The TKE transport by the long wave is significant only in the wave breaking region (Figure 14c). Here, $\overline{\tilde{u}}_{\mathrm{lf}} \tilde{k}_{\mathrm{lf}}$ is directed seaward because TKE is relatively high under the highest waves in the group, when the long-wave velocity is negative (as shown previously). The diffusive transport $\overline{u^{\prime} k^{\prime}}$ is at most locations shoreward (Figure 14d), but magnitudes are small relative to the advective transport rates.

The decomposition in Eq. (4) was also applied to the vertical transport of TKE, results of which are shown in Figure 15. It follows that the net vertical transport is primarily explained by the time-averaged vertical flow component $\bar{w}$, driving a net transport $\bar{w} \bar{k}$ (Figure 15a). These velocities $\bar{w}$ are part of the clockwise mean flow circulation (discussed in Section 4), and are directed upward over $x=55$ to $58 \mathrm{~m}$ and downward over $x=58$ to $60 \mathrm{~m}$. The short-waves contribute to downward transport in the breaking region around $x=59 \mathrm{~m}$ (Figure 15b). This downward transport is explained by relatively high TKE under the rear of the wave, i.e. during the crest-to-trough transition of the water surface. The long-wavedriven vertical transport is negligible (Figure 15c). The diffusive transport (Figure 15d) is downward but it forms a minor contribution to the total net vertical transport.

\section{Discussion}

Similar to previous regular wave studies, the TKE time series and time lags show that TKE at $z-z_{\text {bed }}=$ $0.025 \mathrm{~m}$ is controlled by bed shear only in the shoaling region,. In the breaking and inner surf zones, breaking-generated turbulence appears to control the TKE even at close distance $(0.025 \mathrm{~m})$ from the bed. This is consistent with Van der Zanden et al. (2018), where a smaller roughness was used, and it 
implies that most of the turbulence dynamics in the present study are independent of the applied bed roughness.

The non-dimensional (Froude-scaled) TKE in the wave breaking region varied between $\sqrt{\bar{k} / g h}=0.015$ and 0.03 in the present study. These values are about a factor 3 smaller than values of $\sqrt{\bar{k} / g h}=0.05$ to 0.10 measured under regular plunging waves over plane sloping beaches (see several studies reported by Govender et al., 2002) and a barred bed (van der A et al., 2017). It should be noted that these studies differed not only in terms of water depth but also in terms of wave heights. However, the use of $H_{\max }$ or $\eta_{\text {rms }}$ as Froude length scale still results in Froude-scaled $\bar{k}$ values that are over a factor 2 lower in the present study than in Van der A et al. (2017). Note that although values are presented here for timeaveraged TKE only, a similar difference between the present experiment and the experiment by Van der A et al. (2017) was observed for the Froude-scaled maximum TKE, $\sqrt{\langle k\rangle_{\max } / g h}$.

The relatively low $\sqrt{\bar{k} / g h}$ values in the present study relate likely to the fact that the waves are not regular (non-monochromatic). This would be qualitatively consistent with observations by Scott et al. (2005), who reported TKE under irregular waves to be up to five times lower than under regular waves with similar wave heights. This can physically be understood because the waves in the present study do not all break at the exact same location. Consequently, the injection of turbulence for the present bichromatic waves is more spatially distributed over the surf zone, and the wave-group-averaged production of turbulence by wave breaking is likely of lower magnitude, because some waves pass the bar without breaking. In addition, as shown by Van der Zanden et al. (2018), a significant fraction of TKE in the surf zone originates from local turbulence production in the water column, due to the combination of high turbulent stresses and velocity shear. It is expected that the irregularity of the waves leads to reduced undertow velocity gradients and, consequently, to lower turbulence production rates in the water column compared to regular waves.

The time-dependent TKE differs clearly between the shoaling region, where turbulence is primarily bedshear generated, and the breaking region, where turbulence is generated by wave breaking. The bedgenerated turbulence dissipates quickly, i.e. within one wave cycle after being produced, leading to $\langle k\rangle$ variations at the frequency of a wave cycle and/or wave half-cycle. Turbulence in the wave breaking region, in contrast, decays over multiple wave cycles, and the turbulence production by successive breaking waves in a group leads to a rise and fall of $\langle k\rangle$ at the wave group time scale. The observation of wave breaking turbulence requiring multiple wave cycles to decay, is consistent with observations by Van der A et al. (2017) in a study that involved regular plunging waves (deep-water wave height $H_{0}=$ $0.82 \mathrm{~m}, T=4 \mathrm{~s}$ ) over the same barred bed profile as in the present study. Some studies over plane-sloping beds found that wave breaking TKE dissipates almost fully within one wave cycle (Ting \& Kirby, 1994; De Serio \& Mossa, 2006). Van der A et al. (2017) attributed this difference in relative decay rate to the barred bed profile, since vortices with larger length and time scales can develop under waves plunging into a bar trough relative to those breaking at shallower water over a plane-sloping bed.

In the present study the net cross-shore TKE transport is the balance between an offshore-directed current-related transport by the undertow and an onshore-directed contribution by the short waves, which reaffirms preceding studies (Ting \& Kirby, 1994; van der A et al., 2017). Compared to the study by Van der A et al. (2017) over the same barred bed but with regular plunging waves, the present study indicates a much higher relative magnitude of the wave-related transport compared to the current-related transport. This is largely attributed to the wave (ir)regularity: regular waves produce stronger undertow currents which leads to a higher dominance of the current-related transport of TKE. Another difference with Van der A et al. (2017) is the gravel-bed roughness in the present study, leading to higher bed-shear generated 
TKE which contributes to the onshore-directed wave-related transport of TKE over the offshore slope and bar crest.

Another difference with regular-wave studies is the low-frequency transport, driven by the long wave (also called infragravity wave) induced velocities and the phase-coupling of TKE at the wave group time scale $T_{\mathrm{gr}}$. The present study indicates that in particular between the break and splash point of the wave, concurrently high amplitudes of the long-wave velocity and strong variations of TKE at the wave group time scale can occur, leading to a net transport of TKE by the long wave component. TKE is generally higher when the long-wave velocity is directed offshore, hence the long wave contributes to the seaward transport of TKE. This reaffirms laboratory observations of Brinkkemper et al. (2016) who found highest TKE during negative $u_{\text {lf }}$ under predominantly plunging waves. The results are also consistent with measurements by Ting (2001, 2002), who measured predominantly offshore-directed net transport of TKE by the low-frequency velocities, although these experiments involved spilling breakers. Several studies have shown that the transport of TKE shows strong similarities with the transport of suspended sediment (Brinkkemper et al., 2017; LeClaire \& Ting, 2017; van der Zanden et al., 2017). Consequently, the present study's results on turbulence dynamics at the wave group time scale can contribute to understanding sand resuspension and net sand fluxes at infragravity wave time scales in the surf zone, as observed in several studies (Beach \& Sternberg, 1991; Osborne \& Greenwood, 1992; Ruessink et al., 1998; de Bakker et al., 2016).

Time lags up to 2.5 wave cycles between near-bed TKE and the wave group envelope were observed. This time lag could be interpreted as the combination of a travel time and an "accumulation time", although the latter term, which expresses the build-up of TKE during the wave group cycle, may not be entirely appropriate because TKE is not a mass-conserving quantity: production and dissipation rates are of similar significance in the TKE balance as advection and diffusion rates (e.g., Van der Zanden et al., 2018). The net TKE transport rates in Section 5.4 show that the downward transport is primarily advective, with minor turbulent diffusive contributions, and driven by the vertical component of the time-averaged flow circulation. The time-averaged downward velocities in the breaking region reach values of -0.05 to $-0.10 \mathrm{~m} / \mathrm{s}$, corresponding to TKE travel lags toward the bed of approximately 10 to 20 wave cycles if TKE were only to be spread downward by advection. This does not match the observations of TKE spreading and the quantified time lags which both indicate a lag of about two wave cycles. The explanation is that much of the apparent "TKE spreading" is not due to already existing TKE being advected and/or diffused, but instead, because turbulent vorticity in a shear flow leads to additional, local production of turbulence. Hence, although the periodic velocity leads to minor net downward advection of TKE (see Section 5.4), the orbital motion may contribute to intra-wave vertical spreading of TKE and thus to enhancing TKE production at successive lower elevations.

Morphodynamic models require a high skill in terms of simulating turbulence in order to accurately reproduce the mean flow, sand transport, and morphodynamics in the surf zone. The present study offers new insights that may benefit the advancing of numerical models for surf zone morphodynamics. Firstly, the present study shows that turbulence under wave groups spreads gradually and that TKE time series at the bed may lag wave breaking by a few wave cycles. Depth-averaged models may not be able to reproduce such phase lagging, unless empirical factors are introduced to account for delays in turbulence spreading. A second issue relates to the application of wave-averaged models, in which turbulence is primarily controlled by the mean flow and the short-wave-related transport of TKE is largely neglected. Uncertainty is therefore particularly expected in terms of the significant cross-shore transport of TKE from the shoaling to breaking region. This transport, which is primarily driven by the short waves $\left(\overline{\tilde{u}_{\mathrm{hf}} \tilde{k}_{\mathrm{hf}}}\right)$, is against the direction of the undertow and towards a region with higher TKE and is thus in opposite direction of what would be predicted by a conventional wave-averaged $k-\varepsilon$ model, for example. 
On the other hand, it is expected that an intra-wave, depth-resolving hydrodynamic model is able to reproduce the main processes driving the spatiotemporal distributions of TKE in the surf zone (Lin \& Liu, 1998; Brown et al., 2016). Given their high computational demands, the latter type of models could be used to derive parameterizations for the vertical time lagging of TKE and for the short-wave-related transport of TKE for implementation in wave-averaged and depth-averaged morphodynamic models.

\section{Conclusions}

The spatial and temporal distributions of turbulent kinetic energy (TKE) under bichromatic, plunging breaking waves were studied in a large-scale wave flume. The flow velocities and turbulence were measured with high temporal resolution and spatial coverage across a fixed, gravel-bed breaker bar, covering part of the shoaling region, the full wave breaking region, and part of the inner surf zone. The bichromatic wave produced a wave group with seven incident short waves, of which the highest five waves were plunging breaking over the bar.

The temporal dynamics of TKE vary strongly across the profile. In the shoaling region, where turbulence is primarily bed-shear generated, turbulence decays within one wave cycle, leading to time-varying TKE at the short wave frequency. In contrast, the wave breaking-generated turbulence between plunge and splash points requires multiple wave cycles to decay fully, leading to a gradual increase in TKE during the group and to variations of TKE at the wave group frequency.

As TKE builds up and is gradually transported downward under the train of successive breaking waves, maximum TKE does not occur directly under the largest wave in the group. Instead, maximum TKE near the bed may lag the passage of the highest breaking wave by more than two wave cycles. This time lag depends on the local water depth, with relatively higher time lags over the bar trough relative to the bar crest. Such time lags are virtually absent in the shoaling region, where near-bed turbulence responds almost instantaneously to the local velocity forcing and TKE is maximum under the highest wave in the group.

The cross-shore transport of TKE is shoreward in the shoaling region and seaward in the wave breaking region. The shoreward transport in the shoaling region is explained by a positive phase coupling between velocity and TKE at the short-wave frequency, i.e. TKE is relatively high during the onshore flow halfcycles. The seaward transport of TKE is largely driven by the undertow, with an additional contribution by the long-wave (infragravity) velocity due to a negative phase coupling between TKE and velocity at the wave group frequency. The vertical transport of breaking-generated TKE is primarily driven by the mean flow circulation.

The results in this study contribute to the understanding of surf zone turbulence dynamics at short-wave and wave group time scales. Future studies may focus on further developing numerical models for surf zone TKE and on quantifying the grouped-nature and time lag effects of surf zone turbulence on sediment transport and morphology.

\section{Acknowledgments}

We gratefully acknowledge the suggestions by the three reviewers that helped to improve the manuscript. The work described in this publication was supported by the European Community's Horizon 2020 Programme through the grant to the budget of the Integrated Infrastructure Initiative HYDRALAB+, Contract no. 654110, and was conducted as part of the transnational access project 
685 HYBRID. BEL acknowledges financial support from the Independent Research Fund Denmark project 686 SWASH: Simulating WAve Surf-zone Hydrodynamics and sea bed morphology, Grant no. 802200137B. For their contributions to the experiments, we thank fellow HYBRID researchers and the CIEMLAB staff (Oscar Galego, Andrea Marzeddu, and Joaquim Sospedra). We are grateful to Deltares for lending out their ECMs and to dr Jose Alsina for his contributions to the generation of the wave paddle steering signals. 


\section{References}

Aagaard, T., \& Hughes, M. G. (2010). Breaker turbulence and sediment suspension in the surf zone. Marine Geology, 271(3-4), 250-259. doi:10.1016/j.margeo.2010.02.019

Alsina, J. M., \& Caceres, I. (2011). Sediment suspension events in the inner surf and swash zone. Measurements in large-scale and high-energy wave conditions. Coastal Engineering, 58(8), 657-670. doi:DOI 10.1016/j.coastaleng.2011.03.002

Baldock, T. E., Huntley, D. A., Bird, P. A. D., O'Hare, T., \& Bullock, G. N. (2000). Breakpoint generated surf beat induced by bichromatic wave groups. Coastal Engineering, 39(2-4), 213-242. doi:10.1016/S0378-3839(99)00061-7

Baldock, T. E. (2012). Dissipation of incident forced long waves in the surf zone-Implications for the concept of "bound" wave release at short wave breaking. Coastal Engineering, 60, 276-285. doi:10.1016/j.coastaleng.2011.11.002

Battjes, J. A. (1988). Surf-Zone Dynamics. Annual Review of Fluid Mechanics, 20, 257-293.

Beach, R. A., \& Sternberg, R. W. (1991). Infragravity-driven suspended sediment transport in the swash, inner and outer-surf zone. Proc. Coastal Sediments.

Beach, R. A., \& Sternberg, R. W. (1996). Suspended-sediment transport in the surf zone: Response to breaking waves. Continental Shelf Research, 16(15), 1989-2003.

Bhawanin, M., O'Donoghue, T., Van der A, D. A., \& Ribberink, J. S. (2014). Effect of flow irregularity on oscillatory boundary layer flow. Proc. Int. Conf. on Coastal Engineering (ICCE).

Blott, S. J., \& Pye, K. (2001). GRADISTAT: a grain size distribution and statistics package for the analysis of unconsolidated sediments. Earth Surface Processes and Landforms, 26(11), 12371248. doi:10.1002/esp.261

Boers, M. (2005). Surf zone turbulence. (PhD Thesis), TU Delft, The Netherlands, Delft.

Bonneton, P., Lannes, D., Martins, K., \& Michallet, H. (2018). A nonlinear weakly dispersive method for recovering the elevation of irrotational surface waves from pressure measurements. Coastal Engineering, 138, 1-8. doi:10.1016/j.coastaleng.2018.04.005

Bradford, S. F. (2000). Numerical Simulation of Surf Zone Dynamics. Journal of Waterway, Port, Coastal, and Ocean Engineering, 126(1), 1-13. doi:10.1061/(asce)0733-950x(2000)126:1(1)

Brinkkemper, J. A., Lanckriet, T., Grasso, F., Puleo, J. A., \& Ruessink, B. G. (2016). Observations of turbulence within the surf and swash zone of a field-scale sandy laboratory beach. Coastal Engineering, 113, 62-72. doi:10.1016/j.coastaleng.2015.07.006

Brinkkemper, J. A., de Bakker, A. T. M., \& Ruessink, B. G. (2017). Intrawave sand suspension in the shoaling and surf zone of a field-scale laboratory beach. Journal of Geophysical Research: Earth Surface, 122(1), 356-370. doi:10.1002/2016jf004061

Brown, S. A., Greaves, D. M., Magar, V., \& Conley, D. C. (2016). Evaluation of turbulence closure models under spilling and plunging breakers in the surf zone. Coastal Engineering, 114, 177193. doi:10.1016/j.coastaleng.2016.04.002

Chang, K. A., \& Liu, P. L. F. (1999). Experimental investigation of turbulence generated by breaking waves in water of intermediate depth. Physics of Fluids, 11(11), 3390-3400.

Christensen, E. D., \& Deigaard, R. (2001). Large eddy simulation of breaking waves. Coastal Engineering, 42(1), 53-86. doi:10.1016/S0378-3839(00)00049-1

Christensen, D. F., Brinkkemper, J., Ruessink, G., \& Aagaard, T. (2018). Field observations of turbulence in the intertidal and shallow subtidal zones. Continental Shelf Research, 170, 21-32. doi:10.1016/j.csr.2018.10.002

Cox, D. T., \& Kobayashi, N. (2000). Identification of intense, intermittent coherent motions under shoaling and breaking waves. Journal of Geophysical Research-Oceans, 105(C6), 1422314236. doi:10.1029/2000JC900048

de Bakker, A. T. M., Herbers, T. H. C., Smit, P. B., Tissier, M. F. S., \& Ruessink, B. G. (2015). Nonlinear Infragravity-Wave Interactions on a Gently Sloping Laboratory Beach. Journal of Physical Oceanography, 45(2), 589-605. doi:10.1175/jpo-d-14-0186.1

de Bakker, A. T. M., Brinkkemper, J. A., van der Steen, F., Tissier, M. F. S., \& Ruessink, B. G. (2016). Cross-shore sand transport by infragravity waves as a function of beach steepness. Journal of Geophysical Research: Earth Surface, 121(10), 1786-1799. doi:10.1002/2016jf003878 
De Serio, F., \& Mossa, M. (2006). Experimental study on the hydrodynamics of regular breaking waves. Coastal Engineering, 53(1), 99-113. doi:10.1016/j.coastaleng.2005.09.021

De Serio, F., \& Mossa, M. (2013). A laboratory study of irregular shoaling waves. Experiments in Fluids, 54(6). doi:10.1007/s00348-013-1536-0

Dyhr-Nielsen, M., \& Sorensen, T. (1970). Some sand transport phenomena on coasts with bars. Proceedings of the 12th International Conference on Coastal Engineering, Washington, D.C.

Fernandez-Mora, A., Ribberink, J. S., Van der Zanden, J., van der Werf, J. J., \& Jacobsen, N. G. (2016). RANS-VOF modeling of hydrodynamics and sand transport under full-scale non-breaking and breaking waves. Proceedings of the 35th Conference on Coastal Engineering, Antalya, Turkey.

Folk, R. L., \& Ward, W. C. (1957). Brazos River bar [Texas]; a study in the significance of grain size parameters. Journal of Sedimentary Research, 27(1), 3-26. doi:10.1306/74d70646-2b21-11d78648000102c1865d

Goring, D. G., \& Nikora, V. I. (2002). Despiking Acoustic Doppler Velocimeter Data. Journal of Hydraulic Engineering, 128(1), 117-126. doi:10.1061/(asce)0733-9429(2002)128:1(117)

Govender, K., Mocke, G. P., \& Alport, M. J. (2002). Video-imaged surf zone wave and roller structures and flow fields. Journal of Geophysical Research, 107(C7). doi:10.1029/2000jc000755

Govender, K., Michallet, H., \& Alport, M. J. (2011). DCIV measurements of flow fields and turbulence in waves breaking over a bar. European Journal of Mechanics B-Fluids, 30(6), 616-623. doi:10.1016/j.euromechflu.2011.09.001

Greenwood, B., \& Osborne, P. D. (1990). Vertical and horizontal structure in cross-shore flows: An example of undertow and wave set-up on a barred beach. Coastal Engineering, 14(6), 543-580. doi:10.1016/0378-3839(90)90034-t

Guza, R. T., \& Thornton, E. B. (1980). Local and Shoaled Comparisons of Sea-Surface Elevations, Pressures, and Velocities. Journal of Geophysical Research-Oceans, 85(Nc3), 1524-1530. doi:DOI 10.1029/JC085iC03p01524

Holmes, P., Baldock, T.E., Chan, R.T. and Neshaei, M.A.L., 1997. Beach evolution under random waves. Proc. 25th Int. Conf. on Coastal Eng., pp. 3006-3019, doi 10.1061/9780784402429.233

Jacobsen, N. G., Fredsøe, J., \& Jensen, J. H. (2014). Formation and development of a breaker bar under regular waves. Part 1: Model description and hydrodynamics. Coastal Engineering, 88, 182193. doi:10.1016/j.coastaleng.2013.12.008

Janssen, T. T., Battjes, J. A., \& van Dongeren, A. R. (2003). Long waves induced by short-wave groups over a sloping bottom. Journal of Geophysical Research-Oceans, 108(C8), 1-14. doi:10.1029/2002jc001515

Jonsson, I. G. (1980). A new approach to oscillatory rough turbulent boundary layers. Ocean Engineering, 7(1), 109-152. doi:10.1016/0029-8018(80)90034-7

Lara, J. L., Losada, I. J., \& Liu, P. L. F. (2006). Breaking waves over a mild gravel slope: Experimental and numerical analysis. Journal of Geophysical Research, 111(C11). doi:10.1029/2005jc003374

Lara, J. L., Ruju, A., \& Losada, I. J. (2011). Reynolds averaged Navier-Stokes modelling of long waves induced by a transient wave group on a beach. Proceedings of the Royal Society A: Mathematical, Physical and Engineering Sciences, 467(2129), 1215-1242. doi:10.1098/rspa.2010.0331

Larsen, B. E., \& Fuhrman, D. R. (2018). On the over-production of turbulence beneath surface waves in Reynolds-averaged Navier-Stokes models. Journal of Fluid Mechanics, 853, 419-460. doi:10.1017/jfm.2018.577

LeClaire, P. D., \& Ting, F. C. K. (2017). Measurements of suspended sediment transport and turbulent coherent structures induced by breaking waves using two-phase volumetric three-component velocimetry. Coastal Engineering, 121, 56-76. doi:10.1016/j.coastaleng.2016.11.008

Lin, C., \& Hwung, H. H. (1992). External and Internal Flow-Fields of Plunging Breakers. Experiments in Fluids, 12(4-5), 229-237.

Lin, P., \& Liu, P. L. F. (1998). A numerical study of breaking waves in the surf zone. Journal of Fluid Mechanics, 359, 239-264. doi:10.1017/s002211209700846x

Melville, W. K., Veron, F., \& White, C. J. (2002). The velocity field under breaking waves: coherent structures and turbulence. Journal of Fluid Mechanics, 454, 203-233. doi:10.1017/s0022112001007078 
Mori, N., Suzuki, T., \& Kakuno, S. (2007). Noise of Acoustic Doppler Velocimeter Data in Bubbly Flows. Journal of Engineering Mechanics, 133(1), 122-125. doi:10.1061/(asce)07339399(2007)133:1(122)

Nadaoka, K., \& Kondoh, T. (1982). Laboratory measurements of velocity field structure in the surf zone by LDV. Coastal Engineering in Japan, 25, 125-145.

Nielsen, P. (1984). Field-Measurements of Time-Averaged Suspended Sediment Concentrations under Waves. Coastal Engineering, 8(1), 51-72. doi:10.1016/0378-3839(84)90022-X

Okayasu, A., Shibayama, T., \& Mimura, N. (1986). Velocity Field under Plunging Waves. Proceedings of the 20th International Conference on Coastal Engineering, Taipei, Taiwan.

Osborne, P. D., \& Greenwood, B. (1992). Frequency-Dependent Cross-Shore Suspended Sediment Transport .2. A Barred Shoreface. Marine Geology, 106(1-2), 25-51.

Otsuka, J., Saruwatari, A., \& Watanabe, Y. (2017). Vortex-induced suspension of sediment in the surf zone. Advances in Water Resources, 110, 59-76. doi:10.1016/j.advwatres.2017.08.021

Padilla, E. M., \& Alsina, J. M. (2017). Transfer and dissipation of energy during wave group propagation on a gentle beach slope. Journal of Geophysical Research: Oceans, 122(8), 6773-6794. doi:10.1002/2017jc012703

Peregrine, D. H. (1983). Breaking waves on beaches. Annual Review of Fluid Mechanics, 15(1), 149178. doi:10.1146/annurev.fl.15.010183.001053

Petti, M., \& Longo, S. (2001). Turbulence experiments in the swash zone. Coastal Engineering, 43(1), $1-24$.

Pope, S. B. (2000). Turbulent Flows, Cambridge University Press.

Ribberink, J. S., van der A, D. A., van der Zanden, J., O'Donoghue, T., Hurther, D., Cáceres, I., \& Thorne, P. D. (2014). SandT-Pro: Sediment transport measurements under irregular and breaking waves. Proceedings of the 34th International Conference on Coastal Engineering, Seoul, Korea, Seoul, Korea. 10.9753/icce.v34.sediment.1

Ruessink, B. G., Houwman, K. T., \& Hoekstra, P. (1998). The systematic contribution of transporting mechanisms to the cross-shore sediment transport in water depths of 3 to $9 \mathrm{~m}$. Marine Geology, 152(4), 295-324. doi:10.1016/S0025-3227(98)00133-9

Ruessink, B. G. (2010). Observations of Turbulence within a Natural Surf Zone. Journal of Physical Oceanography, 40(12), 2696-2712. doi:10.1175/2010jpo4466.1

Scott, C. P., Cox, D. T., Maddux, T. B., \& Long, J. W. (2005). Large-scale laboratory observations of turbulence on a fixed barred beach. Measurement Science and Technology, 16(10), 1903-1912. doi:10.1088/0957-0233/19/10/004

Scott, N. V., Hsu, T. J., \& Cox, D. (2009). Steep wave, turbulence, and sediment concentration statistics beneath a breaking wave field and their implications for sediment transport. Continental Shelf Research, 29(20), 2303-2317. doi:10.1016/j.csr.2009.09.008

Smith, E. R., \& Kraus, N. C. (1991). Laboratory study of wave-breaking over bars and artificial reefs. Journal of Waterway, Port, Coastal, and Ocean Engineering, 117(4), 307-325. doi:10.1061/(asce)0733-950x(1991)117:4(307)

Stansby, P. K., \& Feng, T. (2005). Kinematics and depth-integrated terms in surf zone waves from laboratory measurement. Journal of Fluid Mechanics, 529, 279-310. doi:10.1017/S0022112005003599

Stive, M. J. F., \& Wind, H. G. (1982). A Study of Radiation Stress and Set-up in the Nearshore Region. Coastal Engineering, 6(1), 1-25.

Sumer, B. M., Guner, H. A. A., Hansen, N. M., Fuhrman, D. R., \& Fredsoe, J. (2013). Laboratory observations of flow and sediment transport induced by plunging regular waves. Journal of Geophysical Research-Oceans, 118(11), 6161-6182. doi:10.1002/2013jc009324

Svendsen, I. A. (1984). Mass flux and undertow in a surf zone. Coastal Engineering, 8, 347-365.

Svendsen, I. A. (1987). Analysis of Surf Zone Turbulence. Journal of Geophysical Research-Oceans, 92(C5), 5115-5124. doi:10.1029/JC092iC05p05115

Ting, F. C. K., \& Kirby, J. T. (1994). Observation of Undertow and Turbulence in a Laboratory Surf Zone. Coastal Engineering, 24(1-2), 51-80. doi:10.1016/0378-3839(94)90026-4

Ting, F. C. K., \& Kirby, J. T. (1995). Dynamics of Surf-Zone Turbulence in a Strong Plunging Breaker. Coastal Engineering, 24(3-4), 177-204. doi:10.1016/0378-3839(94)00036-W 
Ting, F. C. K., \& Kirby, J. T. (1996). Dynamics of surf-zone turbulence in a spilling breaker. Coastal Engineering, 27(3-4), 131-160. doi:10.1016/0378-3839(95)00037-2

Ting, F. C. K. (2001). Laboratory study of wave and turbulence velocities in a broad-banded irregular wave surf zone. Coastal Engineering, 43(3-4), 183-208.

Ting, F. C. K. (2002). Laboratory study of wave and turbulence characteristics in narrow-band irregular breaking waves. Coastal Engineering, 46(4), 291-313.

van der A, D. A., van der Zanden, J., O'Donoghue, T., Hurther, D., Cáceres, I., McLelland, S. J., \& Ribberink, J. S. (2017). Large-scale laboratory study of breaking wave hydrodynamics over a fixed bar. Journal of Geophysical Research: Oceans, 122(4), 3287-3310. doi:10.1002/2016jc012072

van der Werf, J., Ribberink, J., Kranenburg, W., Neessen, K., \& Boers, M. (2017). Contributions to the wave-mean momentum balance in the surf zone. Coastal Engineering, 121, 212-220. doi:10.1016/j.coastaleng.2016.12.007

van der Zanden, J., van der A, D. A., Hurther, D., Cáceres, I., O'Donoghue, T., \& Ribberink, J. S. (2016). Near-bed hydrodynamics and turbulence below a large-scale plunging breaking wave over a mobile barred bed profile. Journal of Geophysical Research: Oceans, 121(8), 6482-6506. doi:10.1002/2016jc011909

van der Zanden, J., van der A, D. A., Hurther, D., Cáceres, I., O’Donoghue, T., \& Ribberink, J. S. (2017). Suspended sediment transport around a large-scale laboratory breaker bar. Coastal Engineering, 125, 51-69. doi:10.1016/j.coastaleng.2017.03.007

van der Zanden, J., van der A, D. A., Cáceres, I., Hurther, D., McLelland, S. J., Ribberink, J. S., \& O'Donoghue, T. (2018). Near-Bed Turbulent Kinetic Energy Budget Under a Large-Scale Plunging Breaking Wave Over a Fixed Bar. Journal of Geophysical Research: Oceans, 123(2), 1429-1456. doi:10.1002/2017jc013411

Watanabe, Y., Saeki, H., \& Hosking, R. J. (2005). Three-dimensional vortex structures under breaking waves. Journal of Fluid Mechanics, 545(-1), 291. doi:10.1017/s0022112005006774

Xie, Z. (2013). Two-phase flow modelling of spilling and plunging breaking waves. Applied Mathematical Modelling, 37(6), 3698-3713. doi:10.1016/j.apm.2012.07.057

Yoon, H. D., \& Cox, D. T. (2010). Large-scale laboratory observations of wave breaking turbulence over an evolving beach. Journal of Geophysical Research-Oceans, 115. doi:10.1029/2009jc005748

Yoon, H. D., \& Cox, D. T. (2012). Cross-shore variation of intermittent sediment suspension and turbulence induced by depth-limited wave breaking. Continental Shelf Research, 47, 93-106. doi:10.1016/j.csr.2012.07.001

Yu, Y., Sternberg, R. W., \& Beach, R. A. (1993). Kinematics of breaking waves and associated suspended sediment in the nearshore zone. Continental Shelf Research, 13(11), 1219-1242. doi:10.1016/0278-4343(93)90050-8

Yuan, J., \& Dash, S. M. (2017). Experimental investigation of turbulent wave boundary layers under irregular coastal waves. Coastal Engineering, 128, 22-36. doi:10.1016/j.coastaleng.2017.07.005

Zheng, P., Li, M., van der A, D. A., van der Zanden, J., Wolf, J., Chen, X., \& Wang, C. (2017). A 3D unstructured grid nearshore hydrodynamic model based on the vortex force formalism. Ocean Modelling, 116, 48-69. doi:10.1016/j.ocemod.2017.06.003

Zhou, Z., Hsu, T.-J., Cox, D., \& Liu, X. (2017). Large-eddy simulation of wave-breaking induced turbulent coherent structures and suspended sediment transport on a barred beach. Journal of Geophysical Research: Oceans, 122(1), 207-235. doi:10.1002/2016jc011884 


\section{Figures}
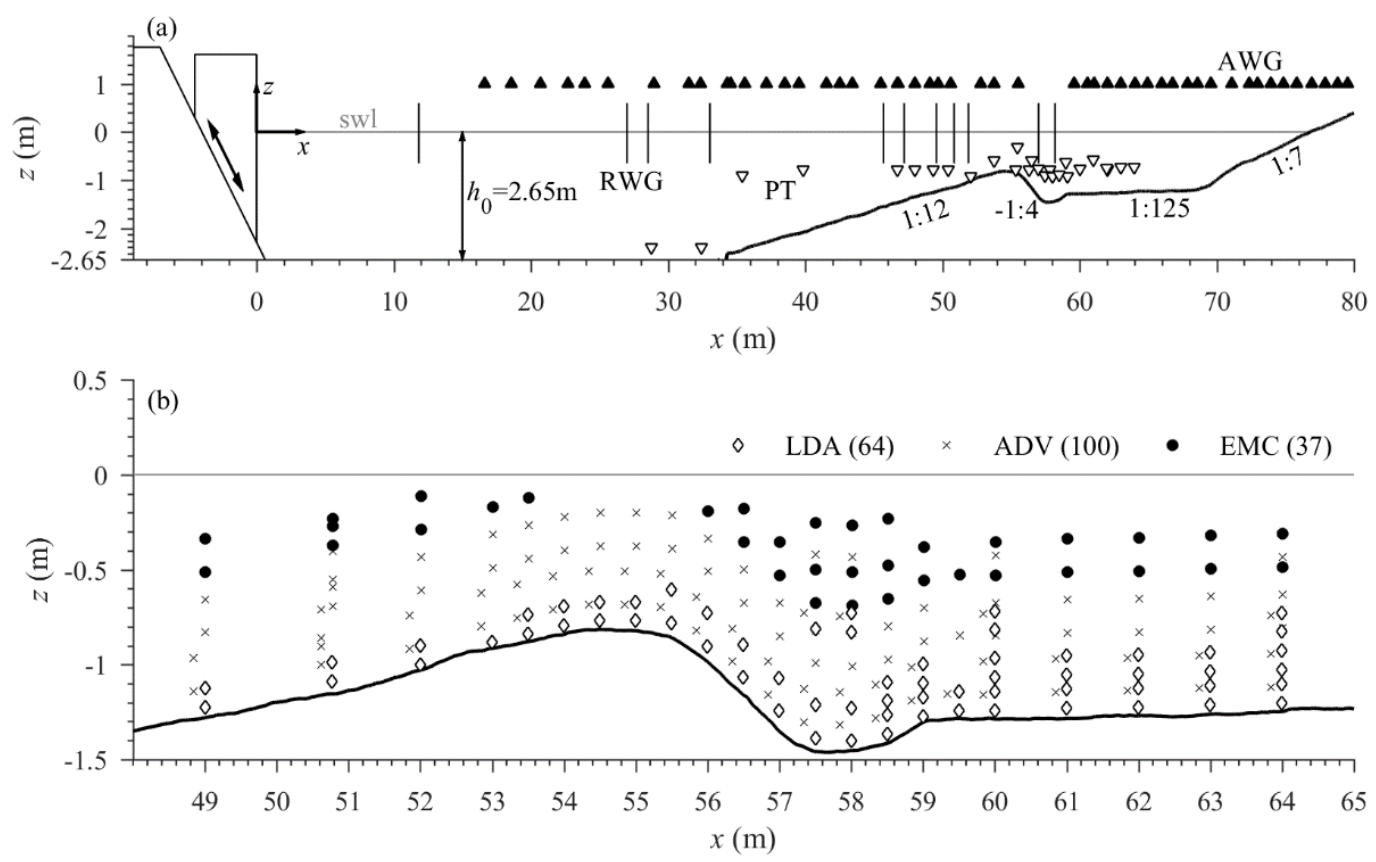

Figure 1. Experimental set-up including measurement locations by: (a) resistive wave gauges (RWG, solid vertical lines), pressure transducers (PT, white triangles), and acoustic wave gauges (AWG, black triangles); (b) laser Doppler anemometers (LDA, diamonds), acoustic Doppler velocimeters (ADVs, crosses), and electromagnetic current meters (EMC, circles), with numbers between brackets indicating the total number of measurement locations by each instrument. 


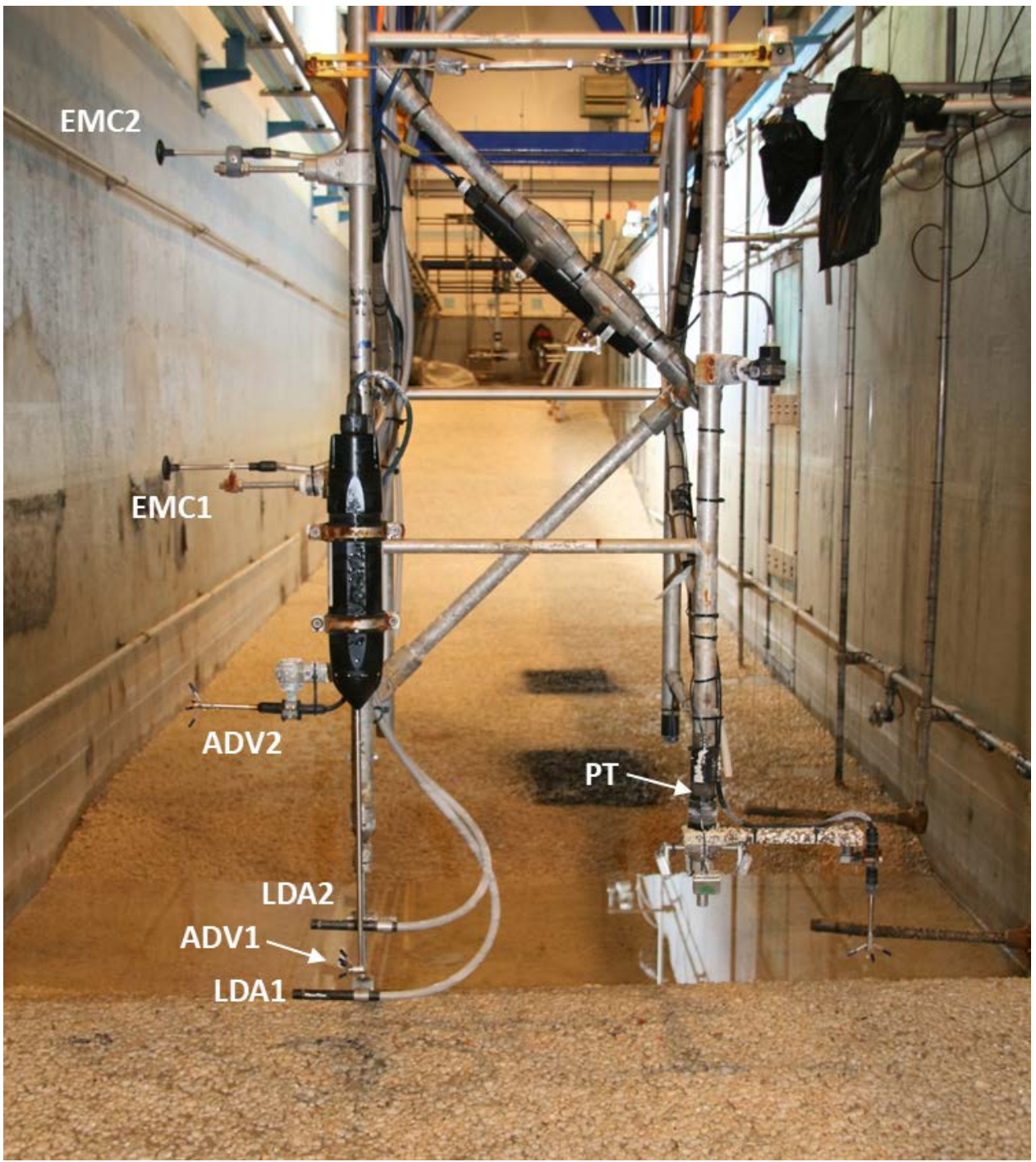

Figure 2. Photo of mobile frame positioned above the bar crest.

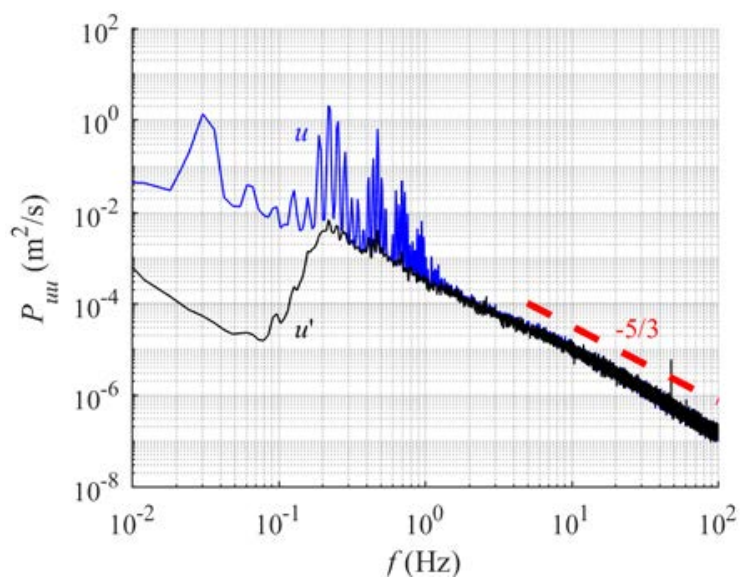

Figure 3. Power spectral density (PSD) of velocity measured by LDA at $x=59.5 \mathrm{~m}$ and $z-z_{\text {bed }}=$ $0.025 \mathrm{~m}$. PSD's are shown of the raw (untreated) velocity time series (blue) and of the cleaned turbulent time series $u$ ' (black). 

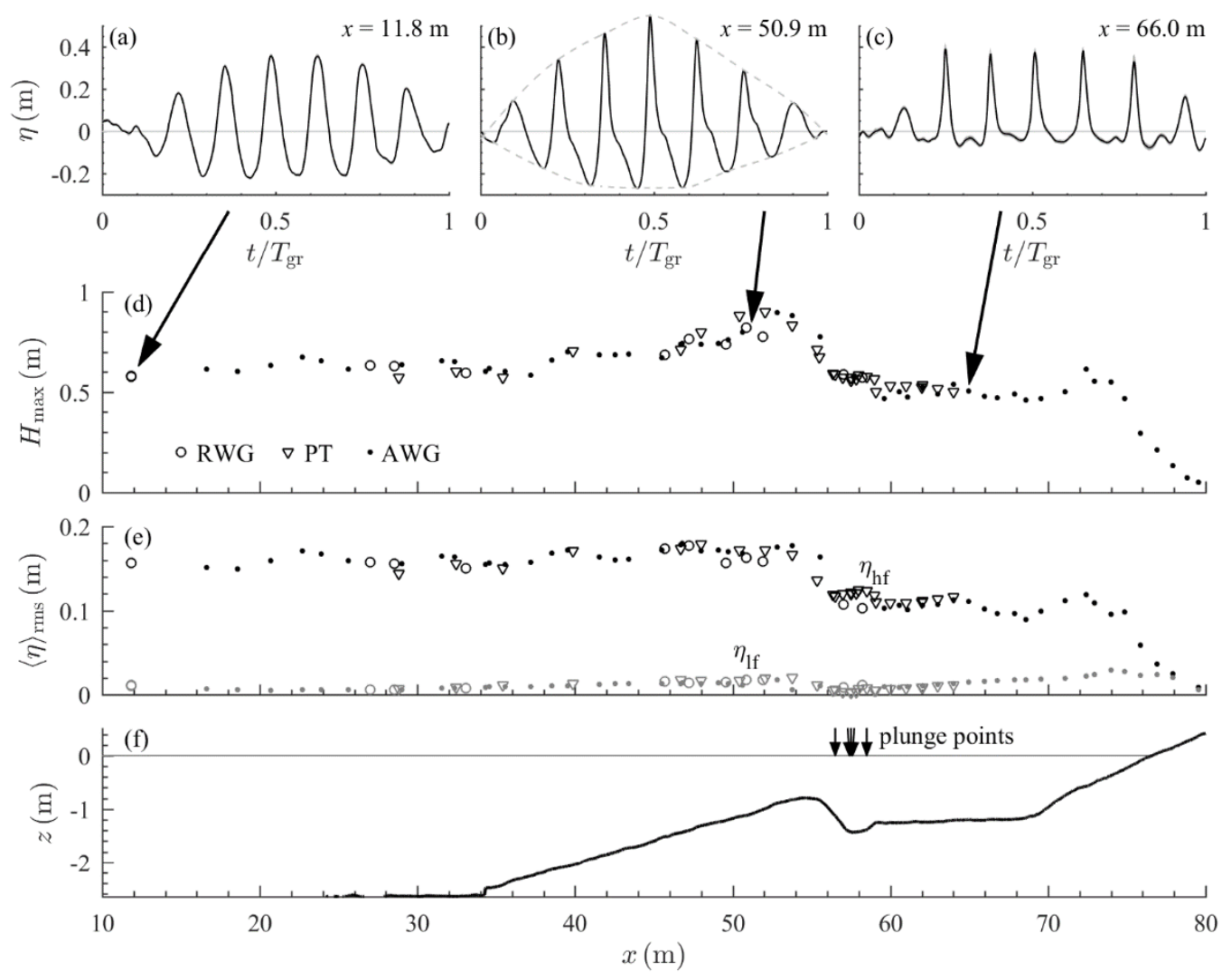

Figure 4. (a-c) Time series of phase-averaged water surface, measured by RWG (a, b) and AWG (c) (solid), with dashed lines in (b) marking the upper and lower bounds of the wave group envelope; (d)

Maximum wave height $H_{\max }=\langle\eta\rangle_{\max }-\langle\eta\rangle_{\min }$, measured by RWGs (circles), PTs (triangles) and AWGs (dots); (e) Root-mean-square water surface elevation, high-frequency (black symbols) and lowfrequency (grey symbols) components; (f) bed profile including locations of the five plunge points. 

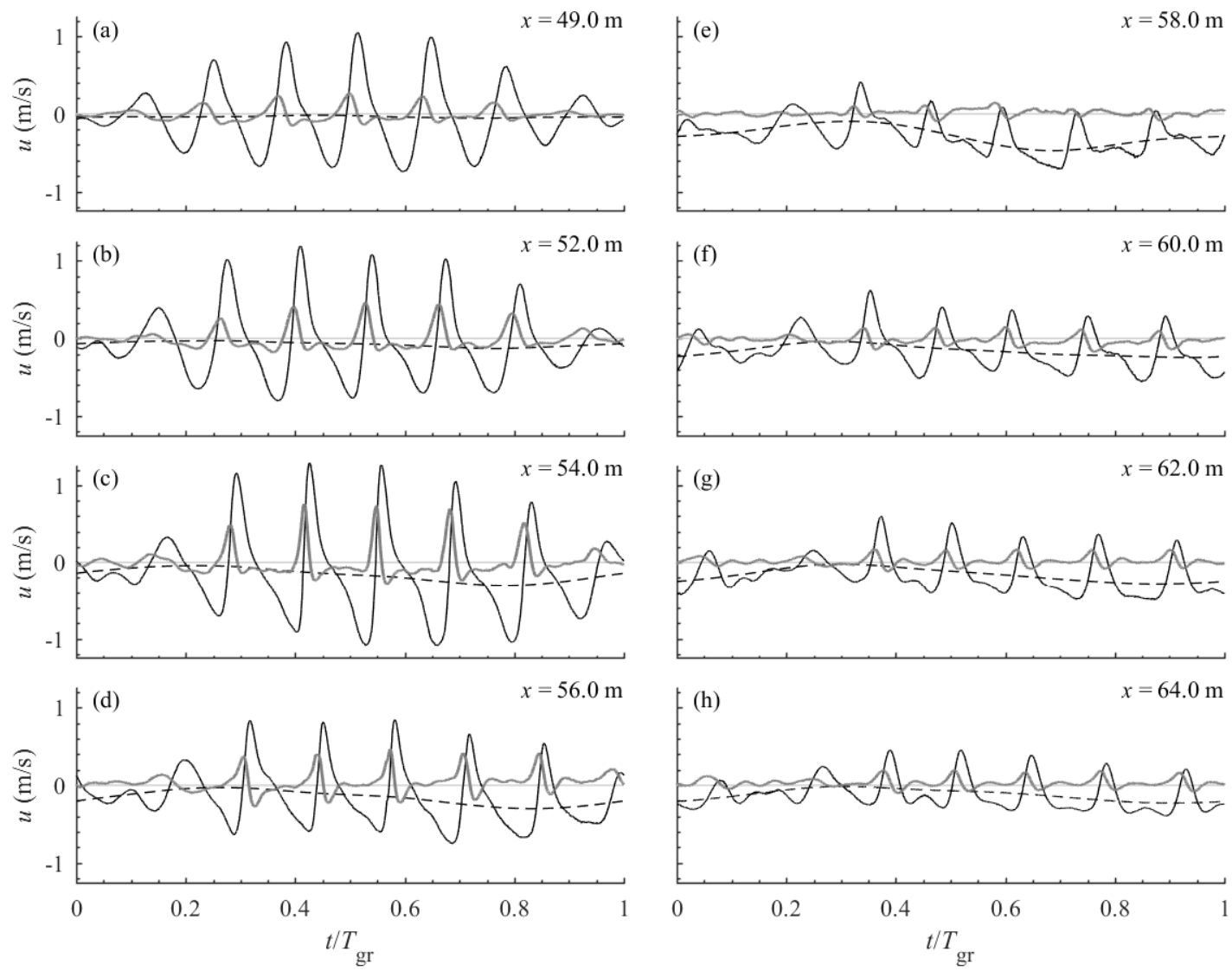

Figure 5. Time series of phase-averaged velocities $\langle u\rangle$ (solid black), $\left\langle\tilde{u}_{\mathrm{lf}}\right\rangle+\bar{u}$ (dashed black), and $\langle w\rangle$ (solid grey) at eight locations and at $z-z_{\text {bed }} \approx 0.40 \mathrm{~m}$. 

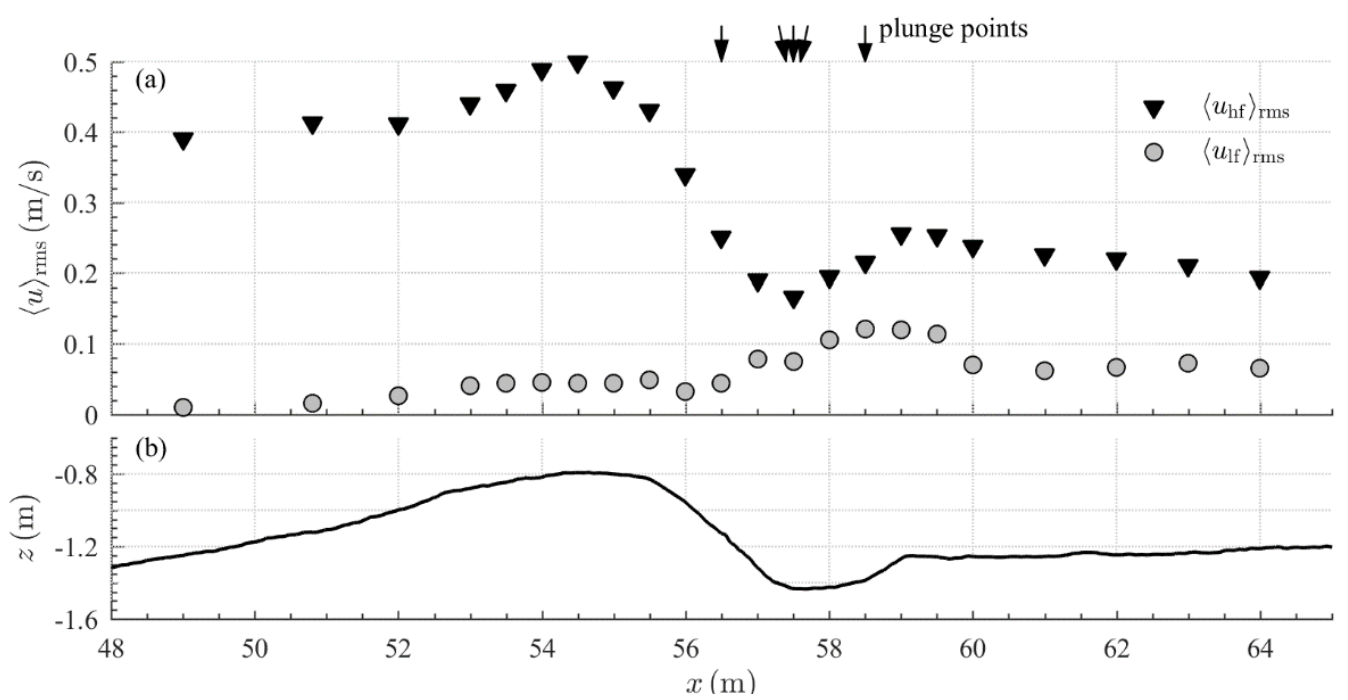

Figure 6. Spatial variation of root-mean-square high- and low-frequency cross-shore velocity at $z-z_{\text {bed }}$ $\approx 0.40 \mathrm{~m}$.

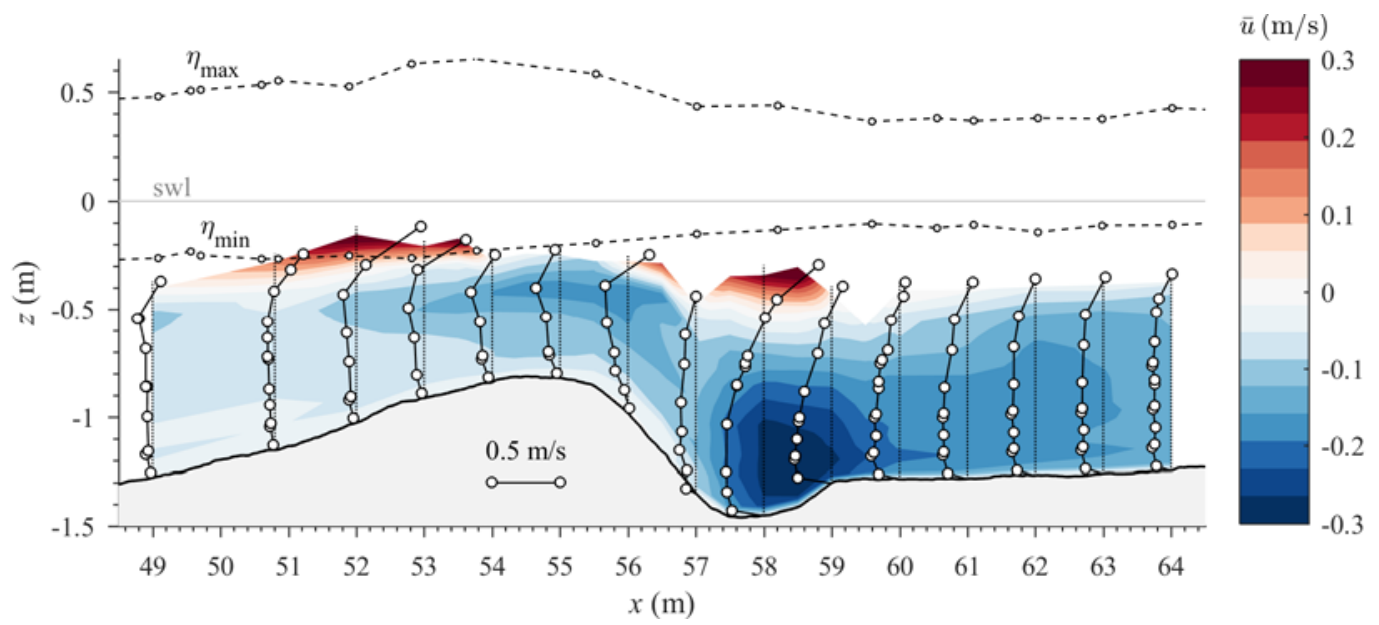

Figure 7. Spatial distribution of time-averaged cross-shore velocity $\bar{u}$. 

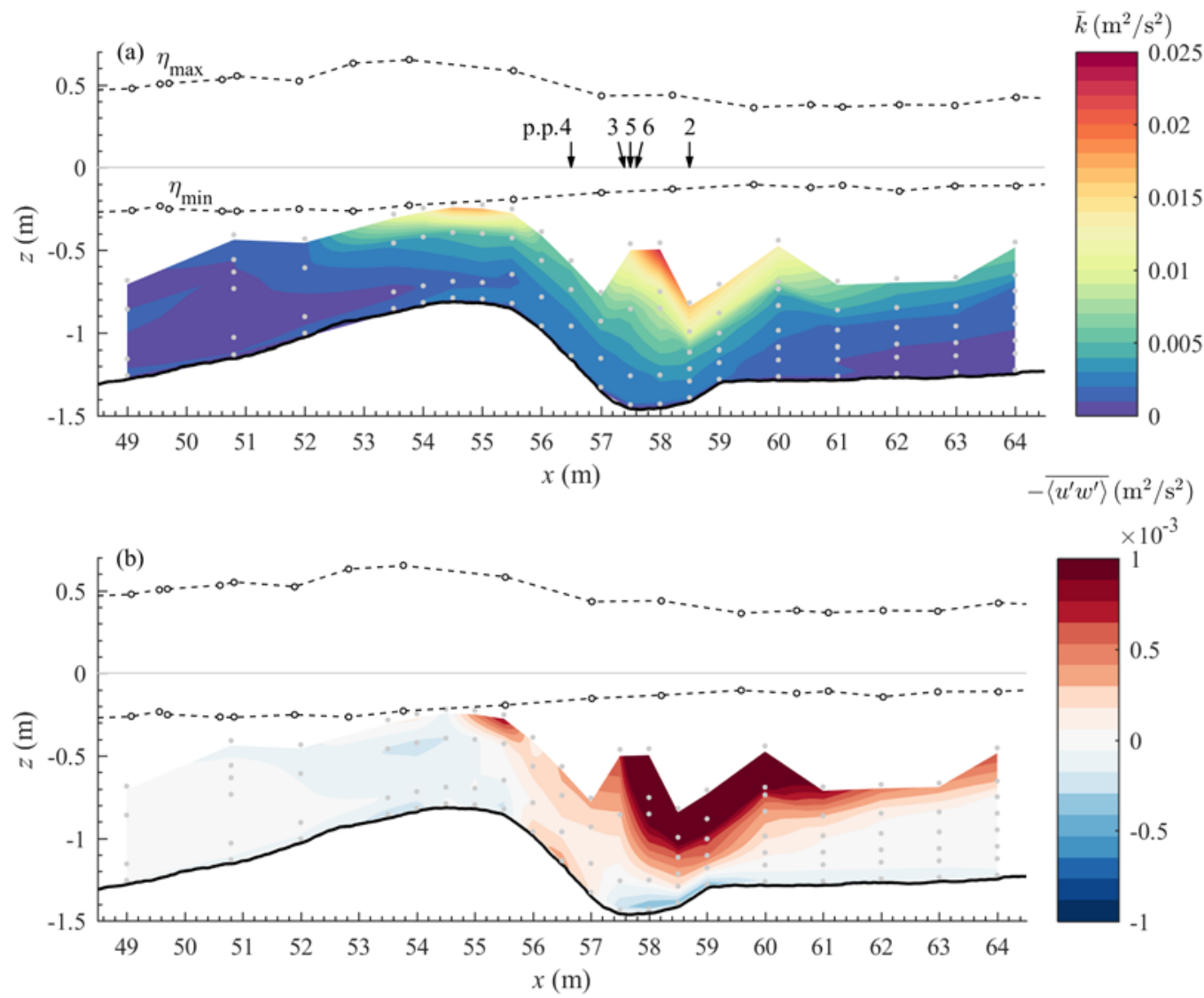

Figure 8. Time-averaged TKE (a) and turbulent Reynolds stress (b). Arrows in upper panel depict the plunge points of the second to sixth wave within the group, grey dots indicate the measurements positions. 

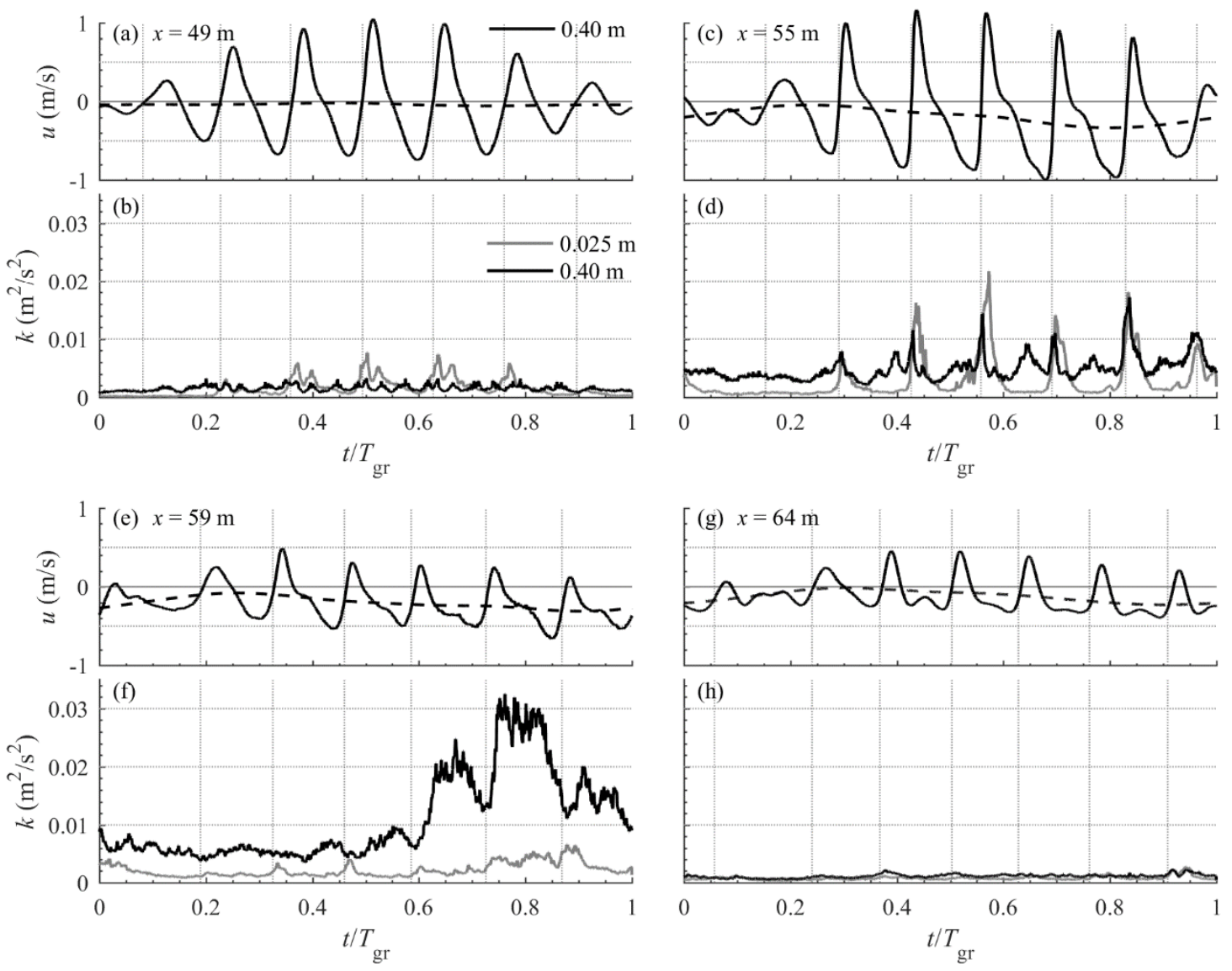

Figure 9. Time series of phase-averaged velocity and TKE at $x=49.0$ (shoaling region), $55.0 \mathrm{~m}$ (bar crest), $59.0 \mathrm{~m}$ (bar trough), and $64.0 \mathrm{~m}$ (inner surf zone). (a, c, e, g) Cross-shore velocity $\langle u\rangle$ (solid) and $\left\langle\widetilde{u}_{\mathrm{lf}}\right\rangle+\bar{u}$ (dashed) at $z-z_{\text {bed }} \approx 0.40 \mathrm{~m}$; (b, d, f, h) TKE at $z-z_{\text {bed }} \approx 0.40 \mathrm{~m}$ (black) and at $z-z_{\text {bed }}=$ $0.025 \mathrm{~m}$ (grey). The vertical grid lines mark the zero-up crossings of $\left\langle\tilde{u}_{\mathrm{hf}}\right\rangle$ at $z-z_{\text {bed }}=0.40 \mathrm{~m}$ at each location. 


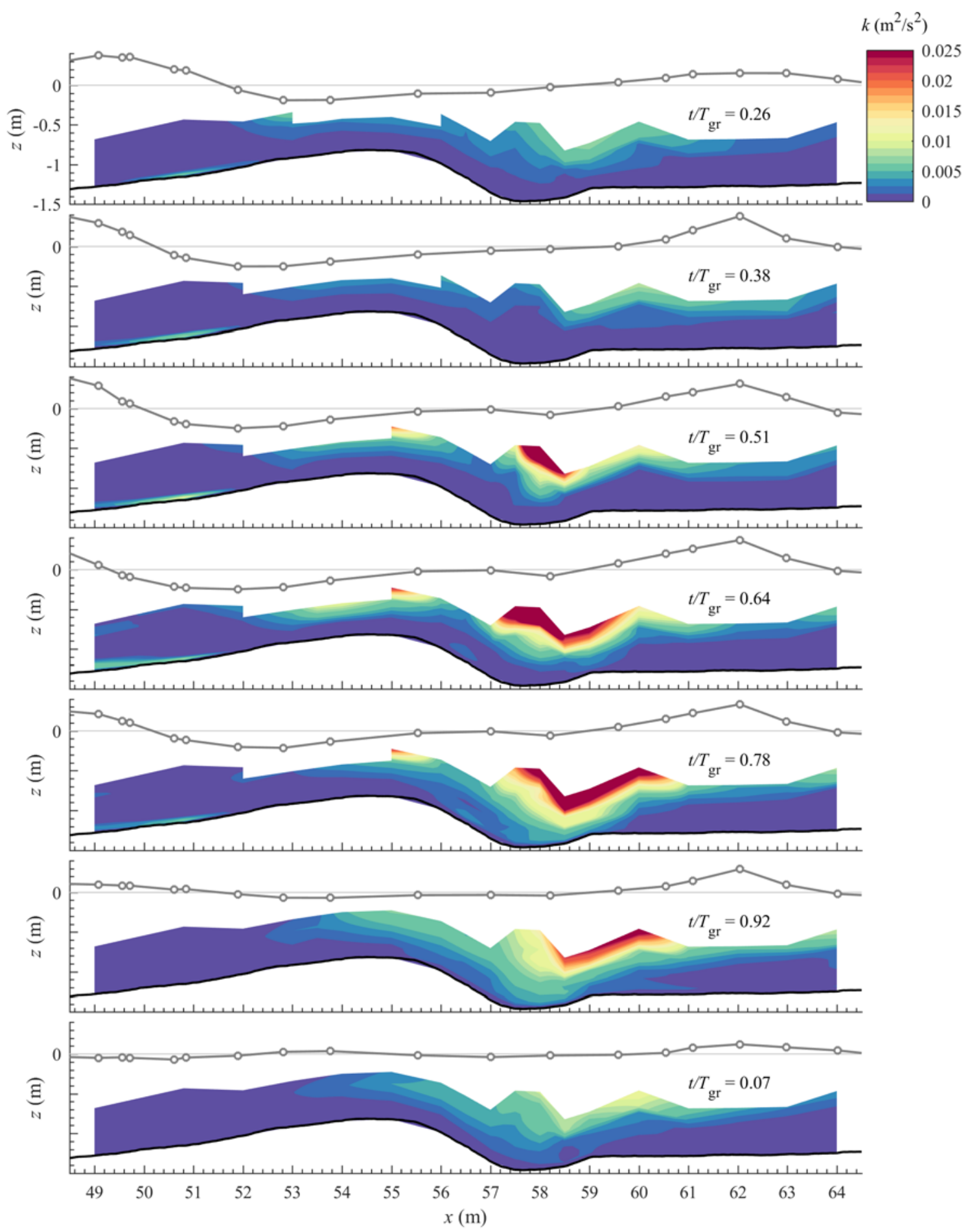

Figure 10. Spatial distributions of phase-averaged TKE at seven phases during the wave cycle, corresponding from top to bottom to the arrival of the seven short waves at $x=62.0 \mathrm{~m}$. The water surface elevation is depicted by the grey circles and line. 

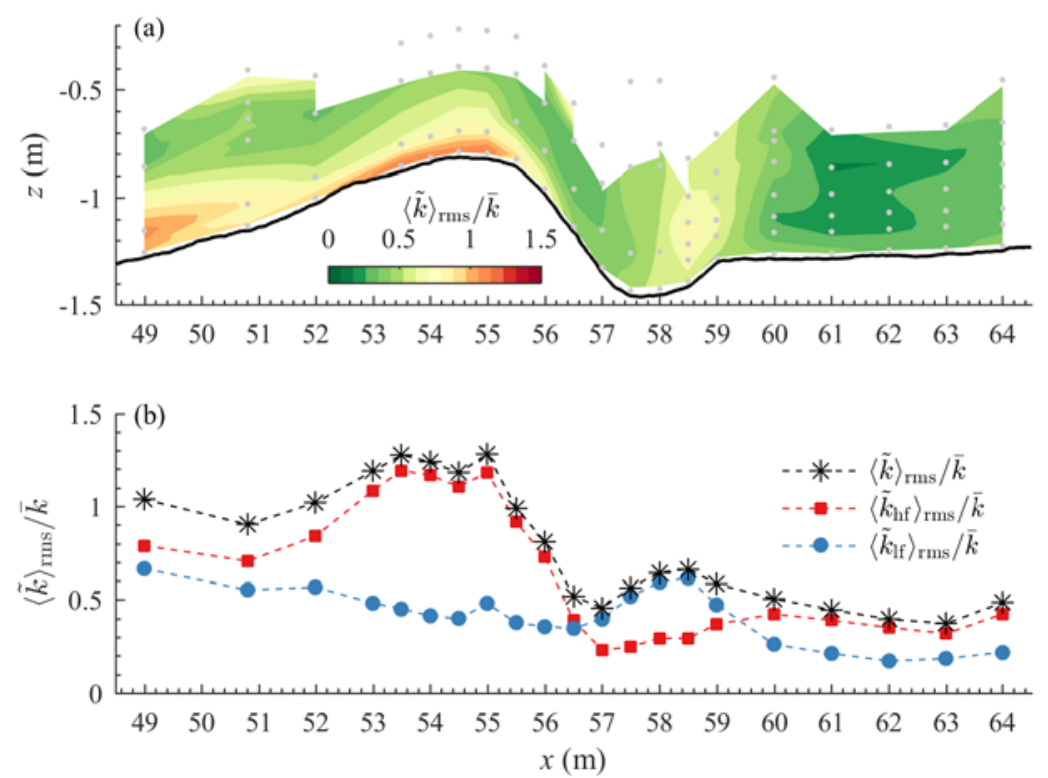

Figure 11. (a) Cross-shore and vertical distribution of the coefficient of variation of TKE, $\langle\tilde{k}\rangle_{\mathrm{rms}} / \bar{k}$, with grey dots indicating measurement positions; (b) Cross-shore distribution of $\langle\tilde{k}\rangle_{\mathrm{rms}} / \bar{k}$ (stars), $\left\langle\tilde{k}_{\mathrm{hf}}\right\rangle_{\mathrm{rms}} / \bar{k}$ (squares) and $\left\langle\tilde{k}_{\mathrm{lf}}\right\rangle_{\mathrm{rms}} / \bar{k}$ (circles) at $z-z_{\text {bed }}=0.025 \mathrm{~m}$. 

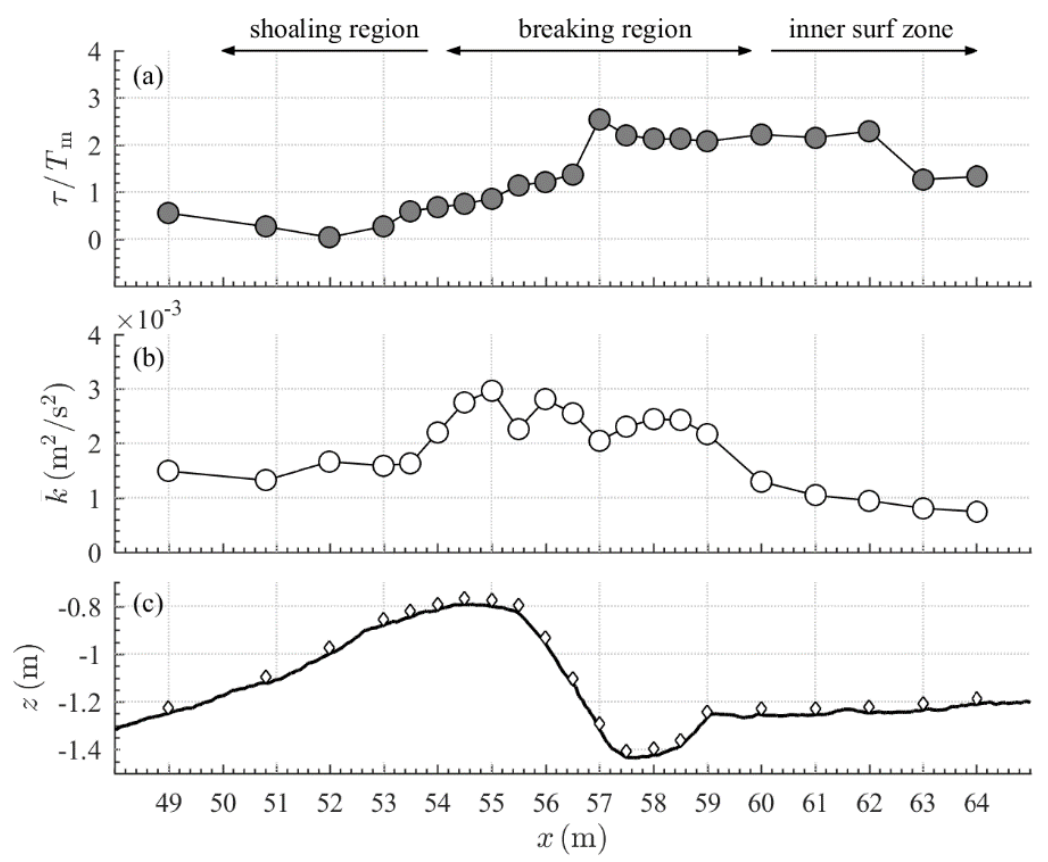

Figure 12. (a) Cross-shore distribution of time lag $\tau$ of near-bed TKE $\left(z-z_{\text {bed }}=0.025 \mathrm{~m}\right)$ w.r.t. center wave in the group; (b) Time-averaged TKE at $z-z_{\text {bed }}=0.025 \mathrm{~m}$; (c) Bed profile, with diamonds indicating measurement locations. 

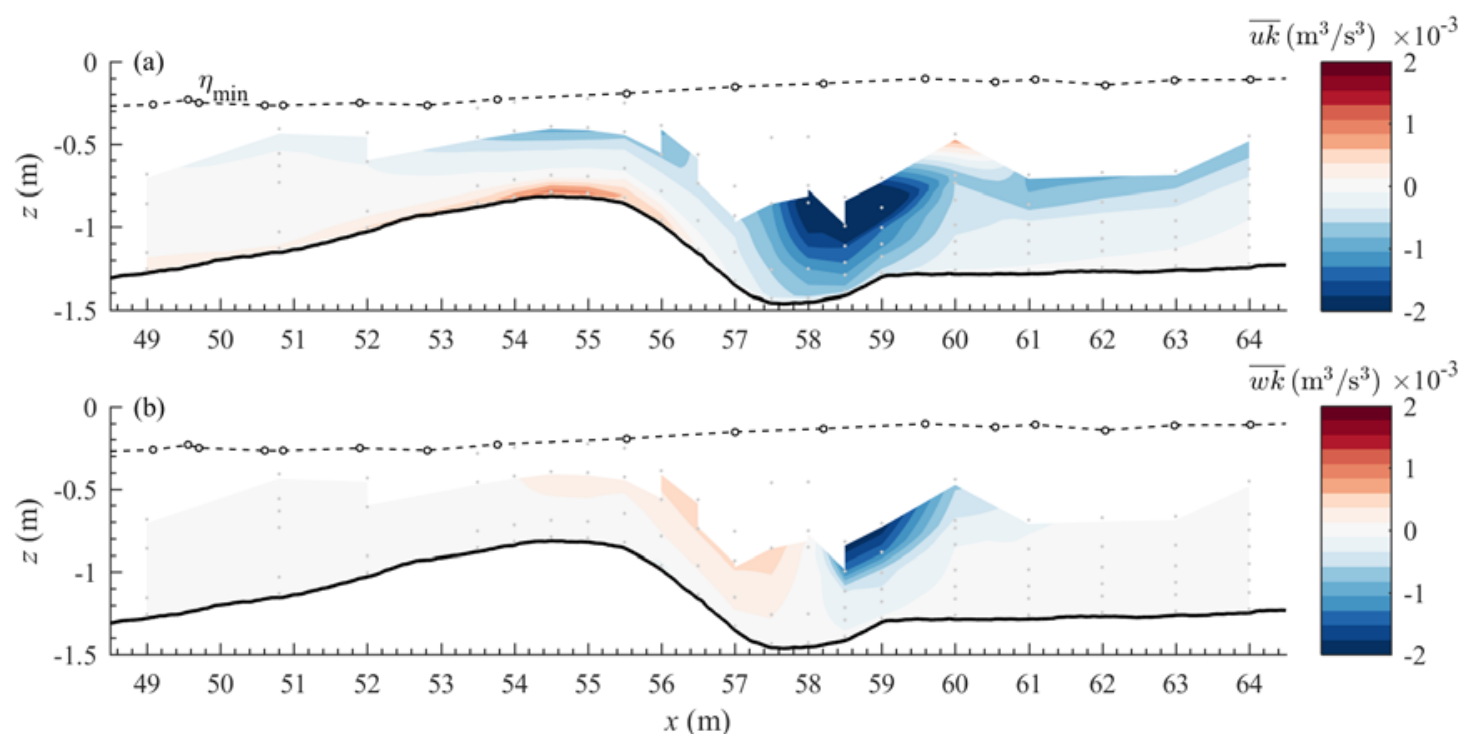

Figure 13. Net total transport of TKE in horizontal (a) and vertical (b) directions. 

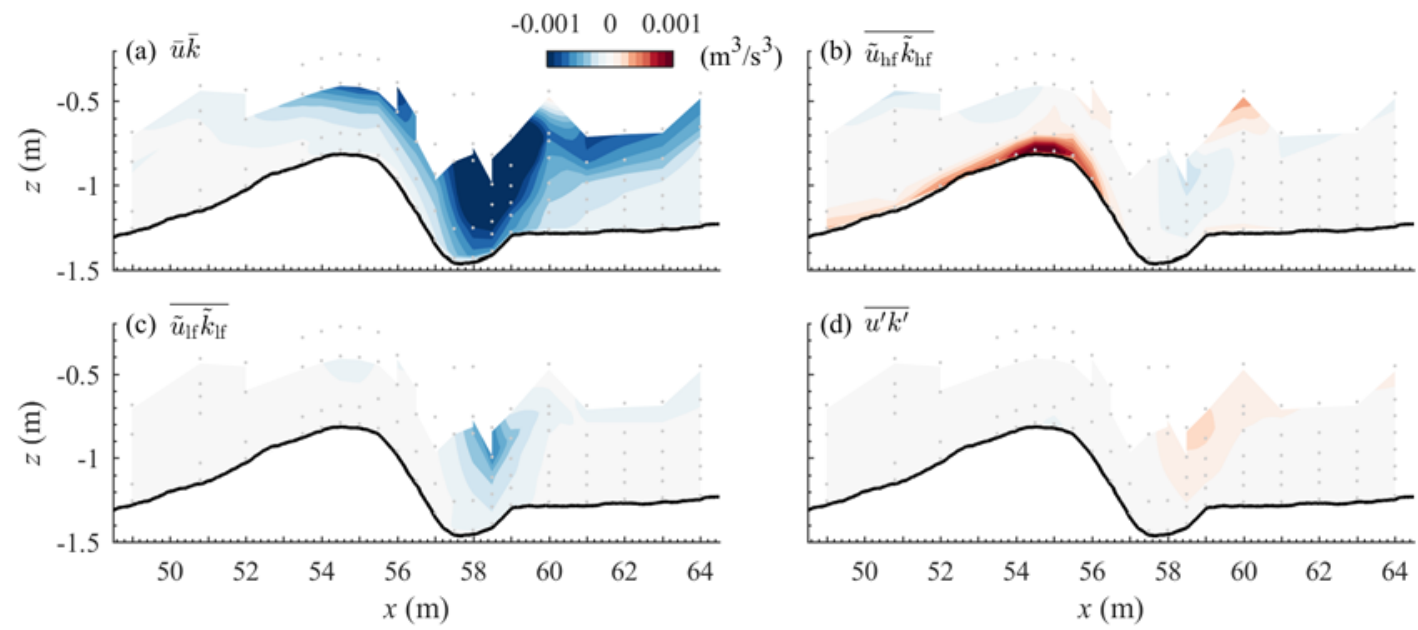

Figure 14. Net cross-shore transport of TKE, decomposed into current-related (a), short-wave-related (b), long-wave-related (c) and diffusive components (d). The same color scale applies to all panels.
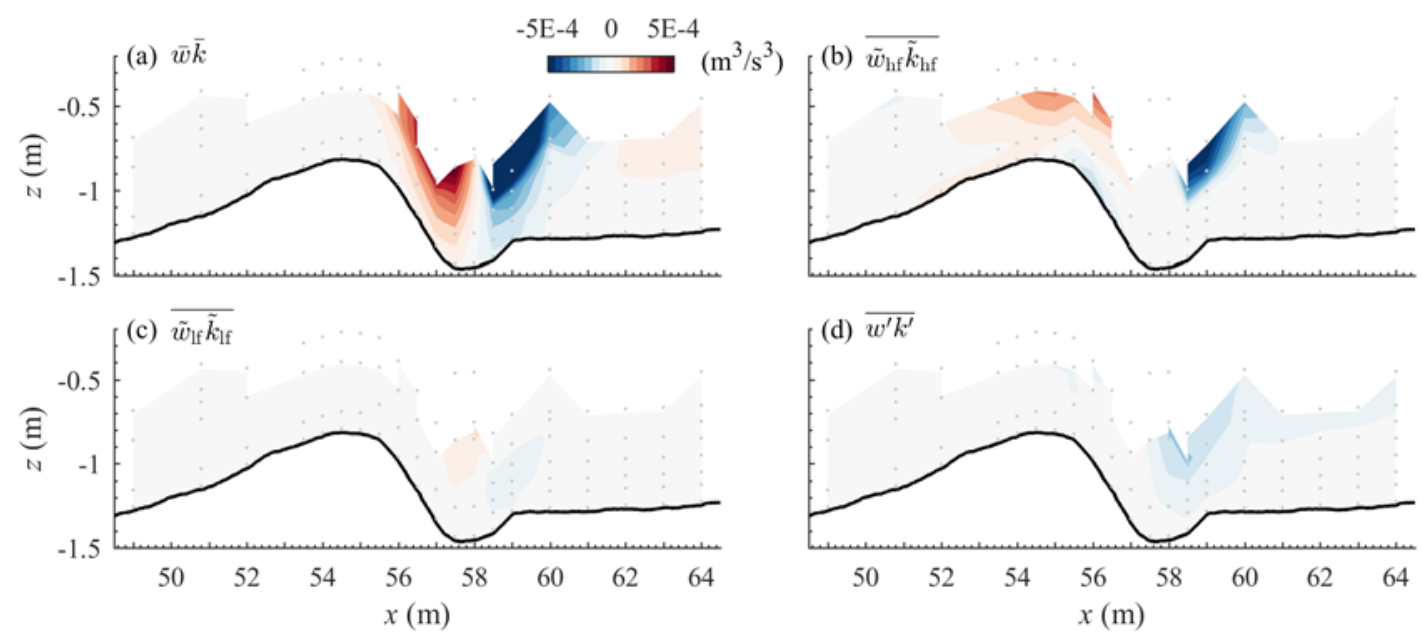

Figure 15. Net vertical transport of TKE, decomposed into current-related (a), short-wave-related (b), long-wave-related (c) and diffusive components (d). The same color scale applies to all panels. 